\title{
Wide Speed Range Operation Strategy of Indirect Matrix Converter-Surface Mounted Permanent Magnet Synchronous Motor Drive
}

\author{
Nuofan Zou ${ }^{1}$, Yan Yan ${ }^{2, *(\mathbb{D})}$, Tingna Shi ${ }^{2}$ and Peng Song ${ }^{2}$ \\ 1 School of Electrical and Information Engineering, Tianjin University, Tianjin 300072, China; \\ zounuofan@tju.edu.cn \\ 2 College of Electrical Engineering, Zhejiang University, Hangzhou 310027, China; tnshi@zju.edu.cn (T.S.); \\ sp_zju@zju.edu.cn (P.S.) \\ * Correspondence: yan_yan@zju.edu.cn; Tel.: +86-0571-87951655
}

check for updates

Citation: Zou, N.; Yan, Y.; Shi, T.; Song, P. Wide Speed Range Operation Strategy of Indirect Matrix Converter-Surface Mounted Permanent Magnet Synchronous Motor Drive. Energies 2021, 14, 2277. https://doi.org/10.3390/en14082277

Academic Editor: Federico Barrero

Received: 19 February 2021

Accepted: 12 April 2021

Published: 18 April 2021

Publisher's Note: MDPI stays neutral with regard to jurisdictional claims in published maps and institutional affiliations.

Copyright: (c) 2021 by the authors. Licensee MDPI, Basel, Switzerland. This article is an open access article distributed under the terms and conditions of the Creative Commons Attribution (CC BY) license (https:// creativecommons.org/licenses/by/ $4.0 /)$.

\begin{abstract}
In order to expand the speed range for an indirect matrix converter-surface mounted permanent magnet synchronous motor drive (IMC-SPMSM), a wide speed range operation control strategy based on a flux-weakening control and an over-modulation method is proposed in this paper. In the stage of the inverter, an IMC over-modulation method is designed, which increases the fundamental voltage transmission ratio (VTR) to 1 . In addition, considering the variation of the voltage limit boundary of the IMC with motor speed, flux-weakening control is implemented based on the voltage error feedback method, which maximizes the voltage utilization rate by setting the endpoint of the output voltage vector on the voltage boundary during the flux-weakening operation. In the stage of the rectifier, over-modulation is automatically switched on or off according to operation requirements by a modulation depth controller. Finally, experimental results show that the proposed strategy increases the maximum speed of the IMC-SPMSM by nearly $35 \%$ compared to the maximum torque per ampere (MTPA) method. Besides, the enlarged voltage margin by the rectifier stage over-modulation effectively shortens the setting time.
\end{abstract}

Keywords: indirect matrix converter; surface mounted permanent magnet synchronous motor; flux-weakening control; over-modulation

\section{Introduction}

Permanent magnet synchronous motors are widely used in aerospace, computational numerical control (CNC) spindle drives, industrial automation, and other fields, which often require a wide speed range, due to their high power density [1]. Flux-weakening and over-modulation are the mostly used methods to obtain a wide speed range for a motor drive system under certain voltage supply and current [2].

The flux-weakening control strategies for a classical vector control system with two inner current loops can be roughly divided into three categories: feedforward strategy, feedback strategy, and hybrid strategy. The feedforward strategy, just as its name implies, feedforwards a compensation component calculated from steady voltage equations of motor into its magnetic current reference. The method in [3] uses a motor equation to calculate current reference values and considers stator resistance voltage drop. In [4], current reference values are calculated by the Newton-Raphson algorithm, and the control accuracy of current set-points can be improved. However, the feedforward strategy suffers limited accuracy, affected by motor parameters. Further, the feedback strategy is proposed to improve robustness of the system. It usually uses voltage amplitude error [5], overmodulation voltage error [6], and action time of the active vector in space vector modulation (SVM) [7], which is not suitable for six-step operation, as feedback. Methods in [6,7] achieve a relatively high voltage utilization rate and therefore greater torque and speed 
output, as they use the voltage vector effectively in the over-modulation region. Several hybrid strategies are proposed by adding the feedback loop into the feedforward path $[8,9]$ and improve performance of flux-weakening control, although the structure of them are comparatively complex.

In the last decades, as a direct $\mathrm{AC}-\mathrm{AC}$ power converter, the indirect matrix converter (IMC) has drawn the attention of researchers on motor drive applications because of its advantages such as no intermediate energy storage, four quadrant operation, sinusoidal input and output waveforms, and adjustable input power factor [10]. Compared with the traditional back-to-back dc-link converters, the control of the IMC is complex, but the absence of bulky electrolytic capacitors in the IMC is foreseen as a more reliable and compact solution for AC-AC power conversion [11]. However, the maximum linear voltage transmission ratio (VTR) of the IMC is only 0.866 , which makes the speed regulation range of the IMC-permanent magnet synchronous motor drive (PMSM) narrower than that of traditional AC-DC-AC converters, and limits its application in industry [12]. Recently, the IMC has made great progress in over-modulation strategy. In $[13,14]$, the over-modulation methods are realized by the linear superimposed principle, which can further improve VTR and reduce the output voltage harmonic components. The over-modulation method in [15] based on predictive control is proposed to improve the input/output current performance, and VTR can reach 0.987 . Although research on over-modulation of matrix converter (MC) has been carried out, few of them concern the flux-weakening control strategy of the IMC-surface mounted permanent magnet synchronous motor drive (SPMSM).

Due to no energy storage device existing in the DC link of the IMC, the input DC voltage of its inverter stage varies periodically, which increases the difficulty of fluxweakening control of the IMC-SPMSM. Moreover, in order to obtain higher VTR and better over-modulation performance, it is necessary to design over-modulation methods of the rectifier stage and inverter stage over-modulation synthetically, which is quite challenging work.

In this paper, firstly, an over-modulation method for the IMC-SPMSM to increase VTR to 1 with linear voltage gain is proposed. Then, by analyzing the particularity of fluxweakening control of the IMC-SPMSM, a coordinated operation mode of flux-weakening controller and rectifier stage modulation depth controller is designed, and a wide speed range flux-weakening control strategy based on voltage error feedback is proposed. For the motor system driven by the IMC, this paper combines over-modulation and fluxweakening control for the first time and applies them to this kind of system. We hope that the research can show some characteristics of this kind of system under the requirements of a wide speed range and provide a solution for broadening the speed range of the system.

\section{Structure of Wide Speed Range Operation Control Strategy for IMC-SPMSM}

The structure diagram of the proposed wide speed range control strategy is shown in Figure 1 . When operating below the rated speed, $i_{\mathrm{d}}=0$ vector control is used. For SPMSM, it achieves maximum torque per ampere (MTPA). Modulation of the rectifier stage is the SVM strategy without zero vector, and that of the inverter stage is the same as the SVM for two-level voltage source inverter (VSI) [16]. When SPMSM operates above the rated speed, the flux-weakening control mode is adopted. The structure diagram of the proposed voltage error feedback flux-weakening control scheme of the IMC-SPMSM is shown in PART_1 of Figure 1.

Modulations of the inverter stage and rectifier stage of the IMC switch between the linear region or the over-modulation region according to the operation requirements (speed reference value and load torque). Specifically, when output of the voltage error feedback fluxing-weakening controller (PART_1) is greater than 0, the flux-weakening control works and modulation of the inverter stage switches to minimum phase error over-modulation [17]. When the output of the rectifier stage modulation depth controller (PART_2) is greater than 0 , modulation of the rectifier stage switches from the linear region to over-modulation. 


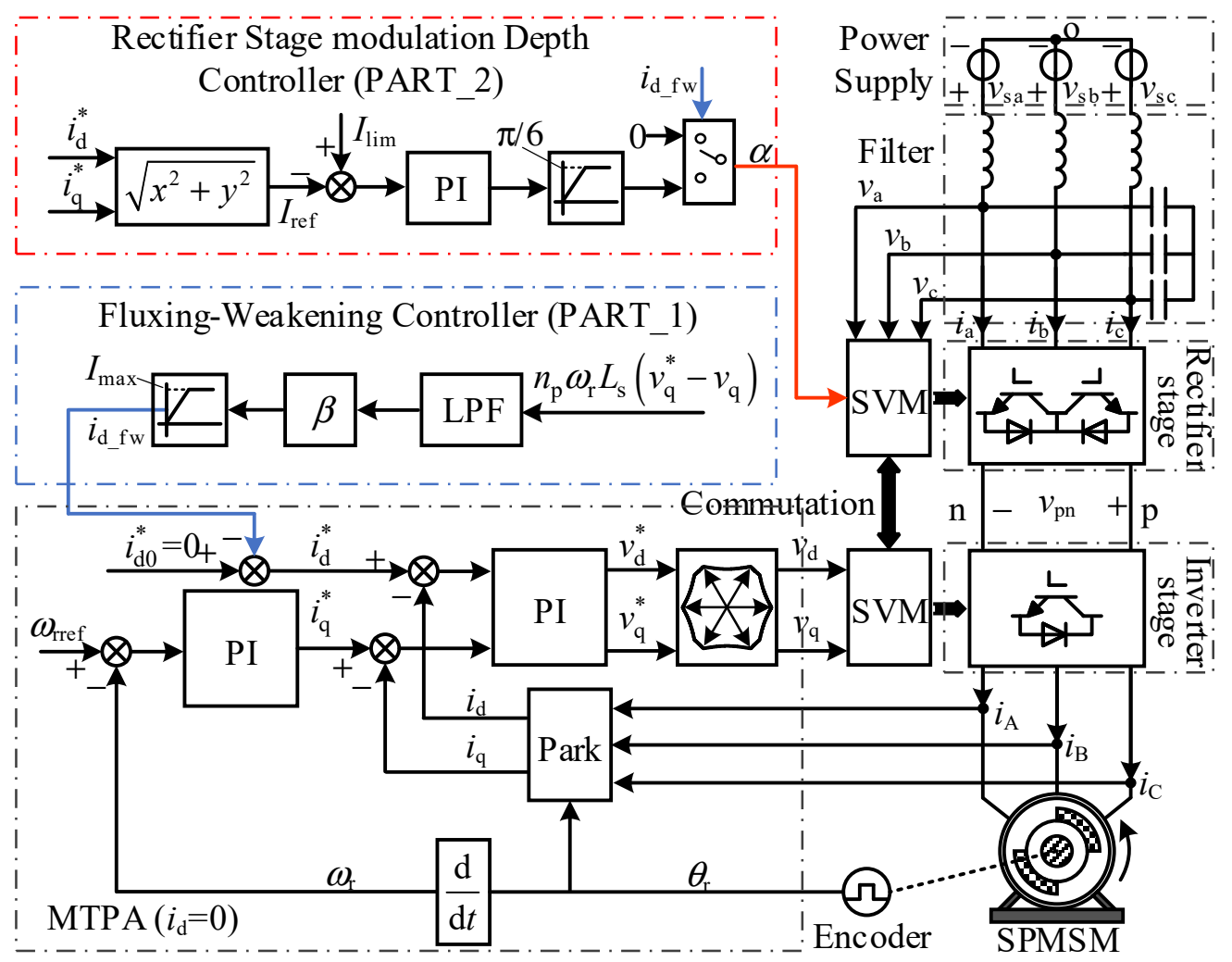

Figure 1. Structure diagram of the proposed wide speed range operation strategy for the indirect matrix converter-surface mounted permanent magnet synchronous motor drive (IMC-SPMSM).

The speed regulation range of the proposed strategy is shown in Figure 2, where $\omega_{\max 1}$, $\omega_{\max 2}$, and $\omega_{\max 3}$ are the maximum operating speeds that can be achieved in different regions. Table 1 summarizes the control strategies and modulation methods that work in different regions (Y stands for working; $q$ stands for range of VTR).

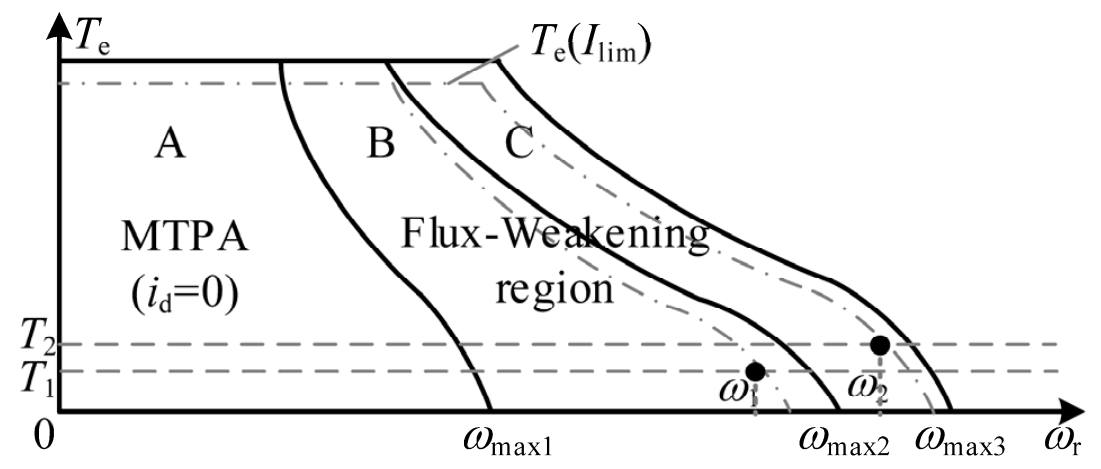
A: MTPA
B: Flux-Weakening + Inverter Stage Modulation
C: B + Rectifier Stage Modulation

Figure 2. Schematic diagram of speed regulation range. 
Table 1. Control strategies or modulation methods activated in different regions.

\begin{tabular}{cccc}
\hline Regions & A & B & C \\
\hline MTPA & Y & & \\
Inverter Stage & & $Y$ & $Y$ \\
Over-modulation & & $Y$ & $Y$ \\
Flux-Weakening & & & $Y$ \\
Rectifier Stage & & $0.866 \sim 0.954$ & $0.954 \sim 1$ \\
Over-modulation & $0 \sim 0.866$ & & \\
$q$ &
\end{tabular}

\section{Modulation Method of IMC-SPMSM}

\subsection{Rectifier Stage Modulation}

It is assumed that three-phase input voltage is

$$
\left\{\begin{array}{l}
v_{\mathrm{a}}=V_{\mathrm{im}} \cos \left(\omega_{\mathrm{i}} t\right) \\
v_{\mathrm{b}}=V_{\mathrm{im}} \cos \left(\omega_{\mathrm{i}} t-2 \pi / 3\right) \\
v_{\mathrm{c}}=V_{\mathrm{im}} \cos \left(\omega_{\mathrm{i}} t+2 \pi / 3\right)
\end{array}\right.
$$

where $V_{\mathrm{im}}$ and $\omega_{\mathrm{i}}$ are amplitude and angular frequency of input voltage, respectively.

Define instantaneous maximum, intermediate, and minimum value of three-phase input voltage as $v_{\text {imax }}=\max \left\{v_{\mathrm{a}}, v_{\mathrm{b}}, v_{\mathrm{c}}\right\}, v_{\text {imid }}=\operatorname{mid}\left\{v_{\mathrm{a}}, v_{\mathrm{b}}, v_{\mathrm{c}}\right\}$, and $v_{\text {imin }}=\min \left\{v_{\mathrm{a}}, v_{\mathrm{b}}, v_{\mathrm{c}}\right\}$, respectively. The input voltages in the unique period can be divided into 12 sectors, as shown in Figure 3a.

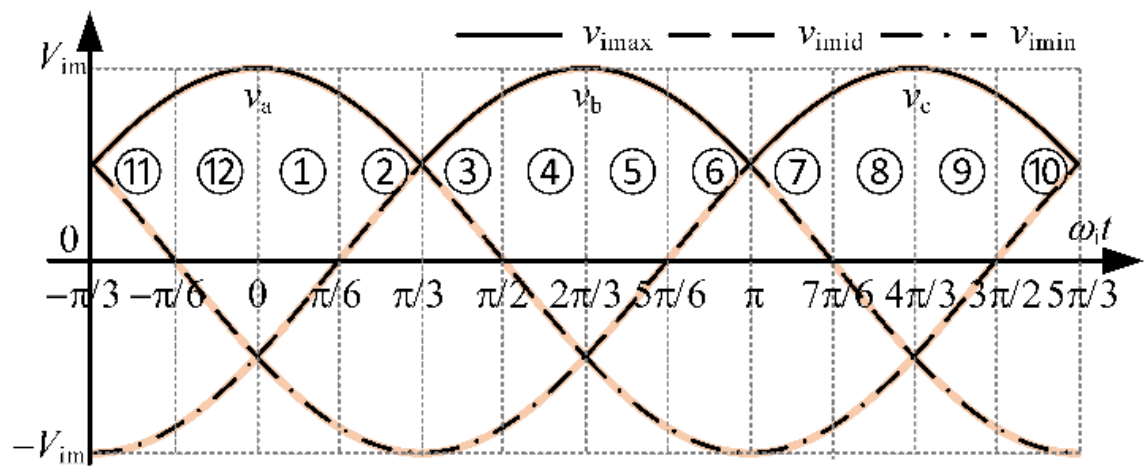

(a)

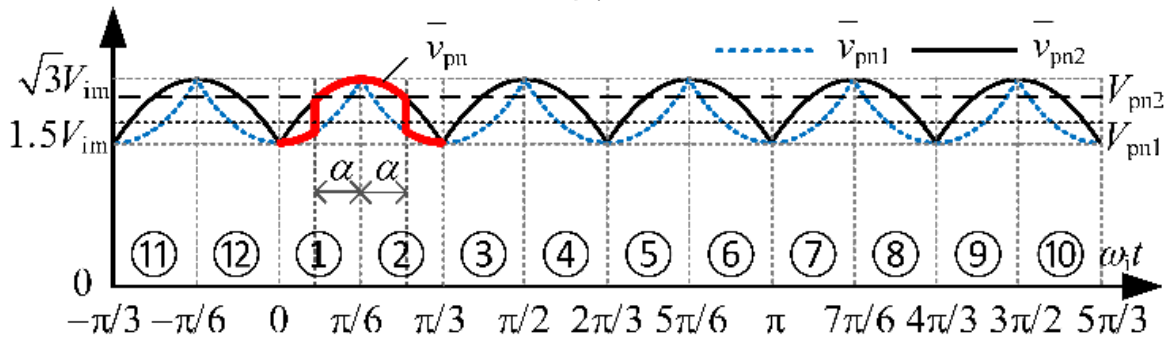

(b)

Figure 3. Schematic diagram of rectifier stage modulation section and $\bar{v}_{\text {pn }}$ waveform. (a) Rectifier stage modulation section; (b) $\bar{v}_{\text {pn }}$ waveform.

Define line voltage as

$$
\begin{gathered}
\Delta v_{\text {imax }}=v_{\text {imax }}-v_{\text {imin }} . \\
\Delta v_{\text {imid }}=\left\{\begin{array}{c}
v_{\text {imax }}-v_{\text {imid }},\left|v_{\text {imax }}\right| \geq\left|v_{\text {imin }}\right| \\
v_{\text {imid }}-v_{\text {imin }},\left|v_{\text {imax }}\right|<\left|v_{\text {imin }}\right|
\end{array} .\right.
\end{gathered}
$$


During each modulation cycle, dc-link voltage $v_{\text {pn }}$ varies in $\left\{\Delta v_{\text {imax }}, \Delta v_{\text {imid }}\right\}$ as power devices switching on and off. Define modulation period of the IMC as $T_{\mathrm{s}}$, the time of $v_{\mathrm{pn}}=\Delta v_{\text {imax }}$ is $T_{\text {max }}$, and the time of $v_{\text {pn }}=\Delta v_{\text {imid }}$ is $T_{\text {mid }}$, then $0 \leq T_{\text {max }}, T_{\text {mid }} \leq T_{\mathrm{s}}$, $T_{\text {max }}+T_{\text {mid }}=T_{\mathrm{s}}$.

In this paper, modulation of the rectifier stage has two modes: CASE 1 and CASE 2. Defined as follows:

CASE 1:

$$
\begin{aligned}
& T_{\text {max }}=\left\{\begin{array}{l}
\frac{\sin \left(\omega_{\mathrm{i}} t-\left(k_{\mathrm{i}}-2\right) \pi / 6\right)}{\cos \left(\omega_{\mathrm{i}} t-\left(k_{\mathrm{i}}-1\right) \pi / 6\right)} T_{\mathrm{s}}, k_{\mathrm{i}} \text { is odd } \\
\frac{\sin \left(\left(k_{\mathrm{i}}+1\right) \pi / 6-\omega_{\mathrm{i}} t\right)}{\cos \left(k_{\mathrm{i}} \pi / 6-\omega_{\mathrm{i}} t\right)} T_{\mathrm{s}}, k_{\mathrm{i}} \text { is even }
\end{array} .\right. \\
& T_{\text {mid }}=\left\{\begin{array}{l}
\frac{\sin \left(k_{\mathrm{i}} \pi / 6-\omega_{\mathrm{i}} t\right)}{\cos \left(\omega_{\mathrm{i}} t-\left(k_{\mathrm{i}}-1\right) \pi / 6\right)} T_{\mathrm{s}}, k_{\mathrm{i}} \text { is odd } \\
\frac{\sin \left(\omega_{\mathrm{i}} t-\left(k_{\mathrm{i}}-1\right) \pi / 6\right)}{\cos \left(k_{\mathrm{i}} \pi / 6-\omega_{\mathrm{i}} t\right)} T_{\mathrm{s}}, k_{\mathrm{i}} \text { is even }
\end{array} .\right.
\end{aligned}
$$

The average value of dc-link voltage in one carrier cycle, $\bar{v}_{\mathrm{pn}}$, of CASE 1 can be derived as

$$
\bar{v}_{\mathrm{pn} 1}=\left\{\begin{array}{l}
3 V_{\mathrm{im}} / 2 \cos \left(\omega_{\mathrm{i}} t-\left(k_{\mathrm{i}}-1\right) \pi / 6\right), k_{\mathrm{i}} \text { is odd } \\
3 V_{\mathrm{im}} / 2 \cos \left(k_{\mathrm{i}} \pi / 6-\omega_{\mathrm{i}} t\right), k_{\mathrm{i}} \text { is even }
\end{array} .\right.
$$

CASE 2:

$$
T_{\text {max }}=T_{\mathrm{s}}, T_{\text {mid }}=0 .
$$

$\bar{v}_{\text {pn }}$ of CASE 2 can be derived as

$$
\bar{v}_{\mathrm{pn} 2}=\left\{\begin{array}{l}
\sqrt{3} V_{\mathrm{im}} \cos \left(k_{\mathrm{i}} \pi / 6-\omega_{\mathrm{i}} t\right), k_{\mathrm{i}} \text { is odd } \\
\sqrt{3} V_{\mathrm{im}} \cos \left(\omega_{\mathrm{i}} t-\left(k_{\mathrm{i}}-1\right) \pi / 6\right), k_{\mathrm{i}} \text { is even }
\end{array}\right.
$$

where $k_{\mathrm{i}}=1,2, \ldots, 12$ is the sector index of input voltage, corresponding to (1), (2), . , (12) in Figure 3.

The waveform of $\bar{v}_{\mathrm{pn}}$ is shown in Figure $3 \mathrm{~b}$. It can be seen that $\bar{v}_{\mathrm{pn} 1}$ and $\bar{v}_{\mathrm{pn} 2}$ varies periodically. The average values of them in each sector can be derived as

$$
\begin{aligned}
& V_{\mathrm{pn} 1}=\frac{6}{\pi} \int_{0}^{\frac{\pi}{6}} \bar{v}_{\mathrm{pn} 1} \mathrm{~d}\left(\omega_{\mathrm{i}} t\right)=\frac{9 \ln 3}{2 \pi} V_{\mathrm{im}} . \\
& V_{\mathrm{pn} 2}=\frac{6}{\pi} \int_{0}^{\frac{\pi}{6}} \bar{v}_{\mathrm{pn} 2} \mathrm{~d}\left(\omega_{\mathrm{i}} t\right)=\frac{3 \sqrt{3}}{\pi} V_{\mathrm{im}} .
\end{aligned}
$$

Based on CASE 1 and CASE 2, an IMC rectifier stage modulation strategy can be constructed as follows, where sector (1) is taken as an example for demonstration.

Defining $\alpha$ as the modulation depth angle of the rectifier stage, when $\omega_{\mathrm{i}} t \in[0, \pi / 6-\alpha)$, CASE 1 is used for the rectifier stage modulation, and $\bar{v}_{\text {pn }}$ is equal to $\bar{v}_{\text {pn } 1}$; when $\omega_{\mathrm{i}} t \in$ $[\pi / 6-\alpha, \pi / 6)$, CASE 2 is used for the rectifier stage modulation, and $\bar{v}_{\text {pn }}$ is equal to $\bar{v}_{\text {pn2 }}$. According to area equivalence, there are

$$
\int_{0}^{\frac{\pi}{6}} V_{\mathrm{pn}} \mathrm{d}\left(\omega_{\mathrm{i}} t\right)=\int_{0}^{\frac{\pi}{6}-\alpha} \bar{v}_{\mathrm{pn} 1} \mathrm{~d}\left(\omega_{\mathrm{i}} t\right)+\int_{\frac{\pi}{6}-\alpha}^{\frac{\pi}{6}} \bar{v}_{\mathrm{pn} 2} \mathrm{~d}\left(\omega_{\mathrm{i}} t\right) .
$$

Substituting (6) and (8) into (11), we have

$$
V_{\mathrm{pn}}=\frac{9 V_{\mathrm{im}}}{\pi}\left[\ln \left(\tan \left(\frac{\pi}{3}-\frac{\alpha}{2}\right)\right)+\frac{2 \sqrt{3}}{3} \sin \alpha\right] .
$$

It can be seen from (12) that when $\alpha \in[0, \pi / 6]$, the average dc-link voltage $V_{\text {pn }} \in$ $\left[9 \ln (3) V_{\mathrm{im}} /(2 \pi), 3 \sqrt{3} V_{\mathrm{im}} / \pi\right]$. In particular, when $\alpha=0$, only CASE 1 works. When $\alpha=\pi / 6$ rad, only CASE 2 works. The calculation method of $\alpha$ will be given in Section 4.3. 


\subsection{Inverter Stage Modulation}

Space vectors and sectors of SVM for the inverter stage of the IMC is shown in Figure 4a. There are six effective vectors $V_{1} \sim V_{6}$ with fixed spatial positions and varying amplitudes, and two zero vectors (uniformly labeled as $V_{0}$ ). The effective vectors divide the complex plane into six sectors. In Figure $4, \varphi_{\mathrm{i}}$ is the input power factor angle, $\varphi_{0}$ is the initial phase angle of the output voltage, $k_{\mathrm{m}}$ is the ratio of angular frequencies of output voltage and input voltage, i.e., $k_{\mathrm{m}}=\omega_{\mathrm{o}} / \omega_{\mathrm{i}}$.

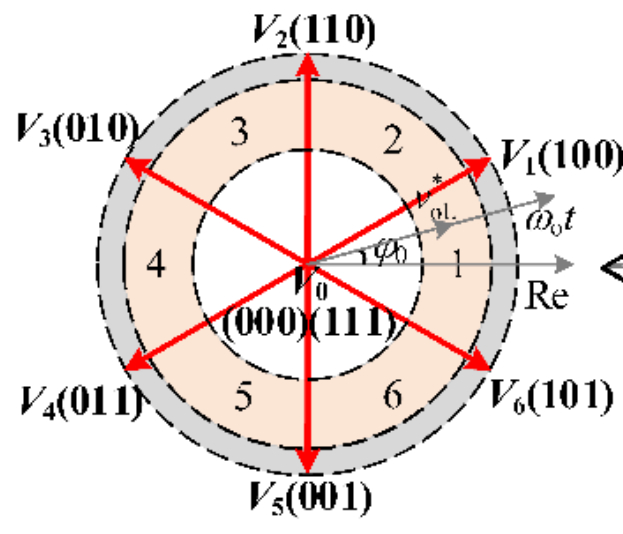

(a)
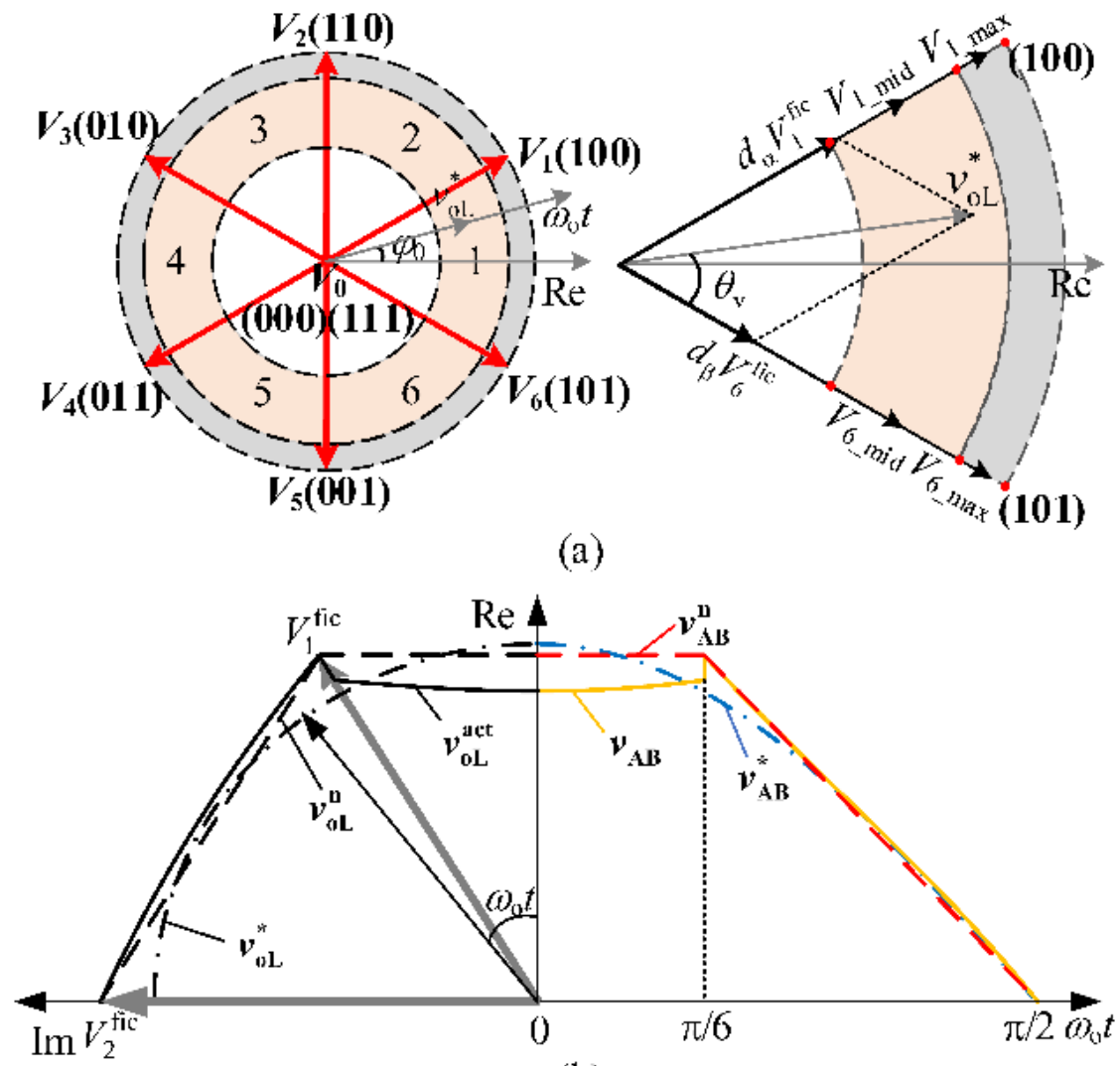

(b)

Figure 4. Diagram of space vector synthesis and trajectory of output voltage vector for the inverter stage of the IMC. (a) Effective space vectors and reference voltage vector synthesis; (b) waveform of output voltage and trajectory of the corresponding vector in the over-modulation region $\left(\varphi_{\mathrm{I}}=0\right.$, $\varphi_{0}=0$, and $\left.k_{\mathrm{m}}=2\right)$.

Since $v_{\mathrm{pn}}$ changes with the modulation process of the rectifier stage, amplitude of the effective vector $V_{l}$ also changes. Supposing that $V_{l}$ is equal to $V_{l_{-} \max }$ and $V_{l_{-} \text {mid }}$ when $v_{\text {pn }}$ is $\Delta v_{\text {imax }}$ and $\Delta v_{\text {imid }}$, respectively, then equivalent basic voltage vectors can be derived as

$$
V_{l}^{\text {fic }}=\left(T_{\max } V_{l \_ \text {max }}+T_{\text {mid }} V_{l_{-} \text {mid }}\right) / T_{\mathrm{s}}=V_{l}^{\mathrm{fic}} \mathrm{e}^{\mathrm{j}\left(\frac{l \pi}{3}-\frac{\pi}{6}\right)}
$$

where $V_{l}^{f \text { ic }}$ is the amplitude of $V_{l}^{\mathrm{fic}}$ and $V_{l}^{\mathrm{fic}}=2 \bar{v}_{\mathrm{pn}} / \sqrt{3} ; l=1,2, \ldots, 6$ is the sector index.

When the reference output line voltage vector $v_{o L}^{*}$ is located in Sector 1 , it can be synthesized from equivalent basic vectors $V_{6}^{\text {fic }}, V_{1}^{\text {fic }}$, and zero vector $V_{0}^{\text {fic }}$.

$$
v_{\mathrm{oL}}^{*}=d_{\alpha} V_{6}^{\mathrm{fic}}+d_{\beta} V_{\mathbf{1}}^{\mathrm{fic}}+d_{0} V_{\mathbf{0}}
$$

where $d_{\alpha}, d_{\beta}$, and $d_{0}$ represent duty cycle of $V_{\mathbf{6}}^{\mathrm{fic}}, V_{\mathbf{1}}^{\mathrm{fic}}$, and $V_{0}^{\mathrm{fic}}$, respectively. 
According to the volt-second balance, $d_{\alpha}$ can be expressed as

$$
\left\{\begin{array}{l}
d_{\alpha}=m_{\mathrm{v}} \sin \left(\pi / 3-\theta_{\mathrm{v}}\right) \\
d_{\beta}=m_{\mathrm{v}} \sin \left(\theta_{\mathrm{v}}\right)
\end{array}\right.
$$

where $\theta_{\mathrm{v}}$ is the angle between $v_{\mathrm{oL}}^{*}$ and $V_{1}^{\mathrm{fic}}, \theta_{\mathrm{v}} \in[0, \pi / 3)$, as shown in Figure $4 \mathrm{a}, m_{\mathrm{v}}$ is the modulation ratio of output voltage, and $m_{\mathrm{v}}=v_{\mathrm{OL}}^{*} / \bar{v}_{\mathrm{pn}}, v_{\mathrm{OL}}^{*}$ is the amplitude of $v_{\mathrm{OL}}^{*}$.

In over-modulation mode, the endpoint of $v_{\mathbf{O L}}^{*}$ is located outside of the regular hexagon constructed by $V_{l}$ fic , and the minimum phase error over-modulation method is used for the inverter stage modulation. The output line voltage vector $v_{\mathbf{o L}}^{\text {act }}$ is kept in phase with $v_{\mathrm{OL}}^{*}$ and its endpoint is located on the boundary of the regular hexagon (note: hexagon radius, $V_{l}^{f i c}=2 \bar{v}_{\text {pn }} / \sqrt{3}$, is variable and not constant), as shown in Figure $4 \mathrm{~b}$. Duty cycles of the minimum phase error over-modulation method can be expressed as

$$
\left\{\begin{array}{l}
d_{\alpha}=\frac{\sin \left(\pi / 3-\theta_{\mathrm{v}}\right)}{\cos \left(\theta_{\mathrm{v}}-\pi / 6\right)} \\
d_{\beta}=\frac{\sin \left(\theta_{\mathrm{v}}\right)}{\cos \left(\theta_{\mathrm{v}}-\pi / 6\right)} .
\end{array}\right.
$$

Expression of output voltage corresponding to $v_{\mathbf{o L}}^{\text {act }}$ is as

$$
v_{\mathrm{AB}}=\left\{\begin{array}{ll}
\frac{\sqrt{3}}{2} V_{l}^{\mathrm{fic}}, & \omega_{0} t+\varphi_{0} \in\left[0, \frac{\pi}{6}\right) \\
\frac{\sqrt{3} V_{l}^{\mathrm{fic}} \cos \left(\omega_{0} t+\varphi_{0}\right)}{2 \cos \left(\frac{\pi}{3}-\omega_{0} t-\varphi_{0}\right)}, & \omega_{0} t+\varphi_{0} \in\left[\frac{\pi}{6}, \frac{\pi}{2}\right)
\end{array} .\right.
$$

Its waveform is shown in Figure $4 b$.

Since $V_{l}^{\text {fic }}$ varies periodically, it is extremely difficult to solve both fundamental voltage from Equation (17) and $\alpha$ required in the regulator stage modulation from Equation (12). In this paper, an approximate calculation method for fundamental voltage is given.

Replacing $\bar{v}_{\mathrm{pn}}$ in $V_{l}^{\text {fic }}=2 \bar{v}_{\mathrm{pn}} / \sqrt{3}$ with $V_{\mathrm{pn}}$ gets

$$
V_{l}^{\mathrm{fic}} \approx \frac{2}{\sqrt{3}} V_{\mathrm{pn}} \mathrm{e}^{j\left(\frac{l \pi}{3}-\frac{\pi}{6}\right)}
$$

The resultant regular hexagon is shown in Figure $4 \mathrm{~b}$ with the dot dashed line.

Construct a vector $v_{\mathbf{o L}}^{\mathbf{n}}$, keep it in phase with $v_{\mathrm{OL}}^{*}$, and locate its endpoint on the regular hexagon of the dot dashed line. Then, expression of $v_{\mathbf{o L}}^{\mathbf{n}}$ in the time domain can be derived as

$$
v_{\mathrm{AB}}^{\mathrm{n}}=\left\{\begin{array}{ll}
V_{\mathrm{pn}}, & \omega_{0} t+\varphi_{0} \in\left[0, \frac{\pi}{6}\right) \\
\frac{V_{\mathrm{pn}} \cos \left(\omega_{0} t+\varphi_{0}\right)}{\cos \left(\frac{\pi}{3}-\omega_{0} t-\varphi_{0}\right)}, & \omega_{0} t+\varphi_{0} \in\left[\frac{\pi}{6}, \frac{\pi}{2}\right)
\end{array} .\right.
$$

Additionally, its waveform is shown in Figure $4 \mathrm{~b}$ as the curve of $v_{\mathrm{AB}}^{\mathrm{n}}$. Then, the fundamental voltage amplitude of $v_{\mathrm{AB}}^{\mathrm{n}}$ can be derived from the Fourier series of Equation (19).

$$
v_{\mathrm{AB}}^{\mathrm{n}}=\frac{3 V_{\mathrm{pn}} \ln 3}{\pi} .
$$

\subsection{IMC High Voltage Transfer Ratio Modulation}

In this paper, VTR is expressed as the ratio of output phase voltage amplitude, $V_{\mathrm{om}}$, and input phase voltage amplitude, $V_{\mathrm{im}}$ :

$$
q=\frac{V_{\mathrm{om}}}{V_{\mathrm{im}}}
$$


From (9), (10), (20), and (21), VTR of the IMC reaches 0.954 and 1, respectively, when the rectifier stage uses CASE 1 and CASE 2 modulation, and the inverter stage uses the minimum phase error over-modulation.

Based on the above analysis, the IMC modulation region can be divided into three parts according to VTR: linear modulation region, over-modulation Region I, and overmodulation Region II.

(1) When $0 \leq q \leq 0.866$, the IMC works in the linear modulation region. Only CASE 1 modulation mode is used in the rectifier stage, and the traditional SVM method is used in the inverter stage.

(2) When $0.866<q \leq 0.954$, the IMC works in over-modulation Region I. Only the CASE 1 modulation mode is used in the rectifier stage, and minimum phase error overmodulation is used in the inverter stage.

(3) When $0.954<q \leq 1$, the IMC works in over-modulation Region II. Both CASE 1 and CASE 2 modulation modes are used in the rectifier stage, and minimum phase error over-modulation is used in the inverter stage.

The process of the proposed modulation method can be described as follows. First, according to input voltage amplitude and expected output voltage amplitude, modulation modes of the IMC rectifier stage and inverter stage are determined, and $\alpha$ is calculated by (12), (20), and (21). Second, the switching time of the inverter stage is calculated by (15) or (16), and the switching time of the rectifier stage is calculated by (4), (5), and (7). These steps ensure the IMC achieves high VTR, which reaches the maximum of 1.

\section{Control Strategy for Wide Speed Range Operation of IMC-SPMSM}

\subsection{Particularity of Flux-Weakening Control in IMC-SPMSM}

In order to facilitate analysis, this paper makes the following assumptions: (1) the saturation of the motor core is ignored; (2) the motor back electromotive force waveform is sinusoidal; (3) the influence of remanence, eddy current, and hysteresis loss is not considered; (4) the rotor has no damping winding and the permanent magnet has no damping effect. In rotor field oriented rotating coordinates, the stator voltage equation and the electromagnetic torque equation of SPMSM can be expressed as [18]

$$
\begin{gathered}
{\left[\begin{array}{c}
v_{\mathrm{d}} \\
v_{\mathrm{q}}
\end{array}\right]=\left[\begin{array}{cc}
R_{\mathrm{s}}+\mathrm{p} L_{\mathrm{s}} & -n_{\mathrm{p}} \omega_{\mathrm{r}} L_{\mathrm{s}} \\
n_{\mathrm{p}} \omega_{\mathrm{r}} L_{\mathrm{s}} & R_{\mathrm{s}}+\mathrm{p} L_{\mathrm{s}}
\end{array}\right]\left[\begin{array}{c}
i_{\mathrm{d}} \\
i_{\mathrm{q}}
\end{array}\right]+\left[\begin{array}{c}
0 \\
n_{\mathrm{p}} \omega_{\mathrm{r}} \lambda
\end{array}\right]} \\
T_{\mathrm{e}}=\frac{3}{2} n_{\mathrm{p}} \lambda i_{\mathrm{q}}
\end{gathered}
$$

where $v_{\mathrm{d}}$ and $v_{\mathrm{q}}$ are $\mathrm{d}-\mathrm{q}$ axes stator voltage; $i_{\mathrm{d}}$ and $i_{\mathrm{q}}$ are $\mathrm{d}$-q axes stator current; $R_{\mathrm{s}}$ is stator resistance; $L_{\mathrm{S}}$ is inductance of stator; $\omega_{\mathrm{r}}$ is angular velocity of rotor; $\mathrm{p}$ is differential operator; $\lambda$ is amplitude of permanent magnetic flux linkage; $n_{\mathrm{p}}$ is number of poles of motor; $T_{\mathrm{e}}$ is electromagnetic torque.

Considering the influence of the IMC capacity, input voltage, modulation method, and motor thermal rating, the voltage and current of SPMSM should meet the following constraints:

$$
\left\{\begin{array}{l}
v_{\mathrm{d}}^{2}+v_{\mathrm{q}}^{2} \leq V_{\max }^{2} \\
i_{\mathrm{d}}^{2}+i_{\mathrm{q}}^{2} \leq I_{\max }^{2}
\end{array}\right.
$$

where $V_{\max }$ is the maximum voltage applied to motor stator winding and $I_{\max }$ is the maximum current flowing in the winding.

Unlike $V_{\max }$ of linear modulation, which is equal to $0.866 V_{\mathrm{im}}$, the instantaneous value of $V_{\max }$ varies with the phase angle of output voltage. The maximum output voltage vector $V_{\text {out_max }}$ can be obtained when the zero vector action time is 0 . The trajectory of the 
endpoint of $\boldsymbol{V}_{\text {out_max }}$ in the complex plane forms the voltage boundary of the IMC, and its amplitude expression is as follows [19]:

$$
V_{\text {out_max }}=\frac{\sqrt{3}}{2} \cdot \frac{\bar{v}_{\text {pn }}}{\cos \left[\omega_{0} t+\varphi_{0}-\pi l / 3+\pi / 6\right]} .
$$

From (6), (8), and (25), $V_{\text {out_max }}$ is related to the input power factor angle $\varphi_{i}$, the output voltage initial phase angle $\varphi_{0}, k_{\mathrm{m}}$, and the modulation mode of the rectifier stage. Figure 5a shows trajectories of the maximum output voltage vectors $V_{\text {out_max1 }}, V_{\text {out_max2 }}$, and $V_{\text {out_max3 }}$ under three different conditions with $\varphi_{\mathrm{I}}=0$ and $\varphi_{0}=0$.

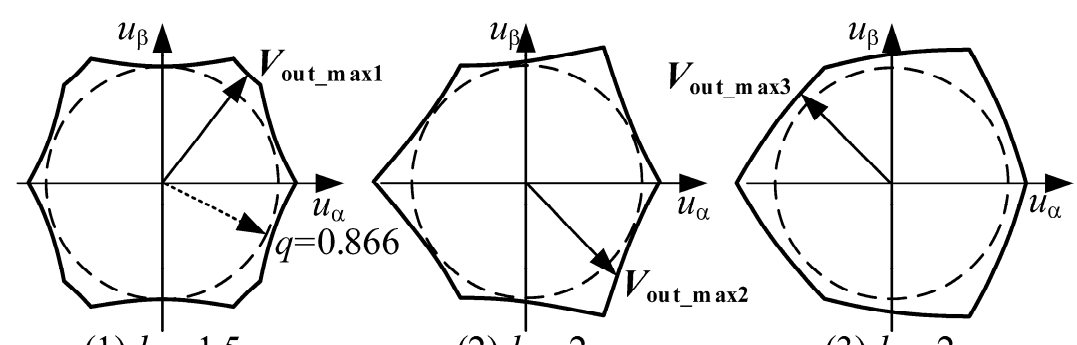

(1) $k_{\mathrm{m}}=1.5$

(2) $k_{\mathrm{m}}=2$

(3) $k_{\mathrm{m}}=2$

CASE 1 Modulation CASE 1 Modulation CASE 2 Modulation

(a)

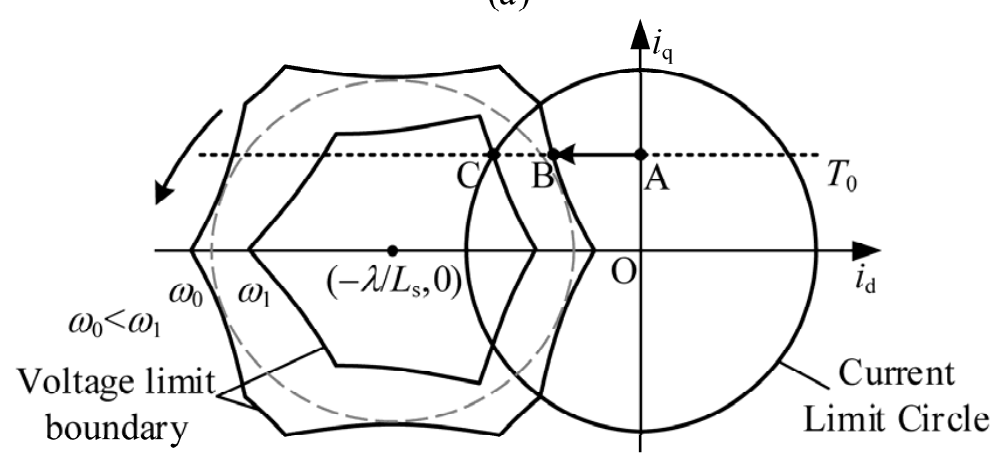

(b)

Figure 5. Trajectory of $V_{\text {out_max }}$, boundary of voltage and current, and trajectory of current vector in the flux-weakening region. (a) Trajectory of $V_{\text {out_max }}$; (b) boundary of voltage and current vectors, and trajectory of current vector in the flux-weakening region.

Ignoring the voltage drop on the stator resistance, the boundary of voltage and current vectors are drawn in the $i_{\mathrm{d}}-i_{\mathrm{q}}$ coordinates according to Equations (22)-(24) and (25), as shown in Figure $5 b$. In the figure, the boundary of current is a limit circle centered at origin, and that of the voltage is some kind of symmetric polygon centered at $\left(-\lambda / L_{\mathrm{s}}, 0\right)$. The higher the speed is, the smaller the radius of the inner tangent circle of the voltage boundary is, and its shape varies in different speeds, as shown in Figure 5b.

As a result, the complexity of the voltage boundary of the IMC-SPMSM under fluxweakening control, i.e., not only the complex shape (symmetric polygon) but also changing with output frequency, burdens the design of the flux-weakening control loop.

\subsection{Flux-Weakening Controller Design}

In order to make full use of the input voltage, the proposed flux-weakening control is based on voltage error feedback. The structure of the controller is shown in PART_1 in Figure 1. Its input signal is the difference between q-axis voltage references before and after over-modulation. Its output signal is used to adjust the d-axis current of motor. 
During the flux-weakening operation, the inverter stage of the IMC works with minimum phase error over-modulation, and the voltage difference before and after overmodulation can be expressed as

$$
\left\{\begin{array}{l}
\Delta v_{\mathrm{d}}=v_{\mathrm{d}}^{*}-v_{\mathrm{d}} \approx-n_{\mathrm{p}} \omega_{r} L_{\mathrm{s}} i_{\mathrm{q} 0}^{*}-v_{\mathrm{d}} \\
\Delta v_{\mathrm{q}}=v_{\mathrm{q}}^{*}-v_{\mathrm{q}} \approx n_{\mathrm{p}} \omega_{r}\left(L_{\mathrm{s}} i_{\mathrm{d} 0}^{*}+\lambda\right)-v_{\mathrm{q}}
\end{array}\right.
$$

where $v_{\mathrm{d}}^{*}$ and $v_{\mathrm{q}}^{*}$ are voltage reference values of $\mathrm{d}$ and $\mathrm{q}$ axes from current regulators, $v_{\mathrm{d}}$ and $v_{\mathrm{q}}$ are the reference values of $\mathrm{d}$ and $\mathrm{q}$ axis voltage after over-modulation, $\mathrm{i}_{\mathrm{d} 0}^{*}$ and $\mathrm{i}_{\mathrm{q} 0}^{*}$ are reference values of $d$ and $q$ axis current under MTPA control.

To minimize the voltage error, a cost function is formulated as

$$
F=\frac{\Delta v_{\mathrm{d}}^{2}+\Delta v_{\mathrm{q}}^{2}}{2} .
$$

By substituting (26) into (27), reference values of the d-axis and q-axis current in the flux-weakening region, $i_{\mathrm{d}}^{*}$ and $i_{\mathrm{q}}^{*}$, can be deduced by the gradient descent method. Generally, for SPMSM drives, $i_{\mathrm{q}}^{*}$ changes slowly in the flux-weakening region, and its derivation can be regarded as zero. Derivations of $i_{\mathrm{d}}^{*}$ and $i_{\mathrm{q}}^{*}$ are as follows:

$$
\frac{\mathrm{d}}{\mathrm{d} t}\left[\begin{array}{c}
i_{\mathrm{d}}^{*} \\
i_{\mathrm{q}}^{*}
\end{array}\right]=-\beta \nabla F=\beta\left[\begin{array}{c}
-n_{\mathrm{p}} \omega_{\mathrm{r}} L_{\mathrm{s}} \Delta v_{\mathrm{q}} \\
0
\end{array}\right]
$$

where $\beta$ is a constant greater than zero. By integrating the two sides of (28), we have

$$
\left[\begin{array}{l}
i_{\mathrm{d}}^{*} \\
i_{\mathrm{q}}^{*}
\end{array}\right]=\left[\begin{array}{c}
i_{\mathrm{d} 0}^{*} \\
i_{\mathrm{q} 0}^{*}
\end{array}\right]+\frac{\beta}{\mathrm{s}}\left[\begin{array}{c}
-n_{\mathrm{p}} \omega_{\mathrm{r}} L_{\mathrm{s}} \Delta v_{\mathrm{q}} \\
0
\end{array}\right] .
$$

It can be seen from (29) that once $\Delta v_{\mathrm{q}}$ beyond $0, i_{\mathrm{d}}^{*}$ cannot restore to $i_{\mathrm{d} 0}^{*}$ due to the integral effect, i.e., control of the system cannot exit the flux-weakening operation region. Therefore, a first-order low-pass filter is used to replace the integrator, and the current reference of the flux-weakening region becomes

$$
\left[\begin{array}{c}
i_{\mathrm{d}}^{*} \\
i_{\mathrm{q}}^{*}
\end{array}\right]=\left[\begin{array}{c}
i_{\mathrm{d} 0}^{*} \\
i_{\mathrm{q} 0}^{*}
\end{array}\right]+\frac{\beta \omega_{\mathrm{c}}}{s+\omega_{\mathrm{c}}}\left[\begin{array}{c}
-n_{\mathrm{p}} \omega_{\mathrm{r}} L_{\mathrm{s}} \Delta v_{\mathrm{q}} \\
0
\end{array}\right]
$$

where $\omega_{\mathrm{c}}$ is the cut-off frequency of the first-order low-pass filter.

In general, $\omega_{\mathrm{c}}$ is set equal to the current regulator bandwidth, i.e., $\omega_{\mathrm{c}}=k_{\mathrm{i}} / k_{\mathrm{p}}$, where $k_{\mathrm{i}}=R_{\mathrm{s}} \omega_{\mathrm{c}}$ and $k_{\mathrm{p}}=L_{\mathrm{s}} \omega_{\mathrm{c}}$. The coefficient $\beta$ has an influence on the range of speed regulation and transient performance of the IMC-SPMSM. A bigger $\beta$ provides stronger flux-weakening ability and better transient performance for current control. Meanwhile, the maximum output torque and the maximum operating speed of the IMC-SPMSM decrease. To keep dimensions of (29) and (30) consistent, $\beta$ can be set as

$$
\beta=1 /\left(n_{\mathrm{p}}^{2} \omega_{\mathrm{rmax}}^{2} L_{\mathrm{s}}^{2}\right)
$$

where $\omega_{\text {rmax }}$ is the maximum operating speed that the motor can reach.

The operation point under the flux-weakening region can be determined as follows: in Figure $5 \mathrm{~b}$, assuming load torque $T_{0}$, during SPMSM speeding up from the below rated speed to $\omega_{0}$, the operating point enters the flux-weakening region at some instant, and then moves from Point $A$ to $B$ along the $T_{0}$ curve. Point $B$, which is the intersection of the voltage boundary and constant torque line, is actually a moving point, as the voltage boundary rotates with an angular velocity of $n_{\mathrm{p}} \omega_{\mathrm{r}}$ in $i_{\mathrm{d}}-i_{\mathrm{q}}$ coordinates. From the derivation process of the current reference in (29), the flux-weakening controller based on (29) keeps the endpoint of the output voltage vector locating on the voltage boundary, so as to make 
full use of the maximum fundamental voltage output by the inverter stage to broaden the speed range of the IMC-SPMSM.

\subsection{IMC Rectifier Stage Modulation Depth Controller Design}

In Figure $5 b$, Point $C$ is the intersection of the current limit circle and voltage boundary, which implies the power limit of the inverter stage of the IMC-SPMSM. To further increase the speed of the motor, a possible way is to adjust modulation depth of the rectifier stage. As stated previously, modulation depth of the rectifier stage is determined by $\alpha$, the modulation depth angle of the rectifier stage. A greater $\alpha$ results in deeper modulation of the rectifier stage, and greater output voltage of the IMC. Consequently, an over-modulation depth controller of the IMC rectifier stage is designed, whose structure is shown as PART_2 in Figure 1. In the figure, the input signal of the controller is the amplitude of the stator current reference vector $I_{\text {ref }}$, and limit of the current, $I_{\lim }\left(I_{\lim }<I_{\max }\right)$. The amplitude expression of $\boldsymbol{I}_{\text {ref }}$ can be expressed as

$$
I_{\mathrm{ref}}=\sqrt{\left(i_{\mathrm{d}}^{*}\right)^{2}+\left(i_{\mathrm{q}}^{*}\right)^{2}} .
$$

Then, $\alpha$ is designed as an output of proportional-integral (PI) regulator to eliminate errors between $I_{\text {ref }}$ and $I_{\text {lim }}$ :

$$
\alpha=\left(I_{\text {ref }}-I_{\text {lim }}\right)\left(k_{\mathrm{pi}}+k_{\mathrm{ii}} / s\right)
$$

where $k_{\mathrm{pi}}$ and $k_{\mathrm{ii}}$ are the proportional and integral coefficients of the rectifier stage modulation depth controller.

The controller represented by (33) may be out of work in some conditions. For example, when the IMC is in over-modulation Region II and $\alpha=\pi / 6$, the output current of the IMC has the most harmonics. The fundamental voltage can be obtained by Fourier expansion as

$$
v_{\mathrm{pn}}=V_{\mathrm{dc}}\left[1-\frac{2}{35} \cos \left(6 \omega_{\mathrm{i}} t+\varphi_{\mathrm{i}}\right)\right] .
$$

When the inverter stage is in the mode of minimum phase error over-modulation, the stator voltage vector moves along the voltage boundary. Assuming the $v_{\mathrm{pn}}$ is constant, then amplitude of the stator voltage vector can be expressed as [20]:

$$
\left\{\begin{array}{c}
v_{\mathrm{s}}=m v_{\mathrm{pn}}\left[1-A \sin \left(6 \omega_{o} t+\varphi_{0}\right)\right] \\
m=\sqrt{2 / \pi} / \sqrt[4]{3}
\end{array}\right.
$$

where $A$ is the fluctuation coefficient of stator voltage in the over-modulation region.

Substituting (34) into (35), we have

$$
\begin{aligned}
v_{\mathrm{s}}= & m V_{\mathrm{dc}}-A m V_{\mathrm{dc}} \sin \left(6 \omega_{0} t+\varphi_{0}\right)-\frac{2}{35} m V_{\mathrm{dc}} \cos \left(6 \omega_{\mathrm{i}} t+\varphi_{\mathrm{i}}\right)- \\
& \frac{1}{35} A m V_{\mathrm{dc}} \sin \left[6\left(\omega_{0}-\omega_{\mathrm{i}}\right) t+\varphi_{\mathrm{i}}-\varphi_{0}\right]+\frac{1}{35} A m V_{\mathrm{dc}} \sin \left[6\left(\omega_{0}+\omega_{\mathrm{i}}\right) t+\varphi_{\mathrm{i}}+\varphi_{0}\right]
\end{aligned}
$$

According to (36), frequencies of stator current harmonics caused by over-modulation are mainly $6 \omega_{\mathrm{o}}, 6 \omega_{\mathrm{i}}, 6\left(\omega_{\mathrm{o}}-\omega_{\mathrm{i}}\right)$, and $6\left(\omega_{\mathrm{o}}+\omega_{\mathrm{i}}\right)$.

Ignoring stator resistance, the relationship between stator currents and stator voltages in the steady state can be obtained from (22).

$$
\left\{\begin{array}{l}
i_{\mathrm{d}}=\left(v_{\mathrm{q}}-\omega_{\mathrm{o}} \lambda\right) / \omega_{\mathrm{o}} L_{\mathrm{s}} \\
i_{\mathrm{q}}=v_{\mathrm{d}} /\left(-\omega_{\mathrm{o}} L_{\mathrm{s}}\right)
\end{array} .\right.
$$


Taking frequency of $6 \omega_{\mathrm{i}}$ as an example, and ignoring the change of stator inductance, the amplitude of the stator current harmonic is calculated as

$$
\left\{\begin{array}{l}
i_{\mathrm{d} \_6 \omega_{\mathrm{i}}}=2 m V_{\mathrm{dc}} \cos \left(\varphi_{v}\right) /\left(35 \omega_{\mathrm{o}} L_{\mathrm{s}}\right) \\
i_{\mathrm{q} \_6 \omega_{\mathrm{i}}}=2 m V_{\mathrm{dc}} \sin \left(\varphi_{v}\right) /\left(-35 \omega_{\mathrm{o}} L_{\mathrm{s}}\right) \\
I_{\mathrm{sm} \_6 \omega_{\mathrm{i}}}=\sqrt{i_{\mathrm{d} \_6 \omega_{\mathrm{i}}}^{2}+i_{\mathrm{q} \_6 \omega_{\mathrm{i}}}^{2}}
\end{array}\right.
$$

where $\varphi_{v}$ is the angle between the stator voltage vector and d-axis, $I_{\mathrm{sm} \_} 6 \omega \mathrm{i}$ is the amplitude of the current harmonic with a frequency of $6 \omega_{\mathrm{i}}$.

Other amplitudes of current harmonics such as $I_{\mathrm{sm} \_} 6 \omega_{0}, I_{\mathrm{sm} \_} 6\left(\omega_{\mathrm{o}}-\omega_{\mathrm{i}}\right)$, and $I_{\mathrm{sm} \_} 6\left(\omega_{\mathrm{o}}+\omega_{\mathrm{i}}\right)$ can be similarly calculated. It should be noticed that if the difference between $I_{\mathrm{lim}}$ and $I_{\max }$ is less than peak value of those current harmonics, then the regulator tends to be saturated and output a constant $\alpha$ of $\pi / 6$. As a result, the difference between $I_{\lim }$ and $I_{\max }$ is set to be greater than the current harmonic peak value by $I_{\max }-I_{\lim } \geq \max \left\{I_{\mathrm{sm} \_} 6 \omega_{\mathrm{i}}, I_{\mathrm{sm} \_} 6 \omega_{0}\right.$, $\left.I_{\mathrm{sm} \_} 6\left(\omega_{\mathrm{o}}-\omega_{\mathrm{i}}\right), I_{\mathrm{sm} \_6\left(\omega_{\mathrm{o}}+\omega_{\mathrm{i}}\right)}\right)$.

\subsection{Analysis of Operation Point with the Proposed Flux-Weakening Control Strategy}

Taking the speed-up and loading process of the IMC-SPMSM in the flux-weakening region as an example, Figure 6 shows how the operation point of the system changes. In the figure, $\omega_{1}$ and $\omega_{2}$ represent rotor angular velocity and $\omega_{2}>\omega_{1} ; T_{1}$ and $T_{2}$ represent load torque and $T_{2}>T_{1}$.

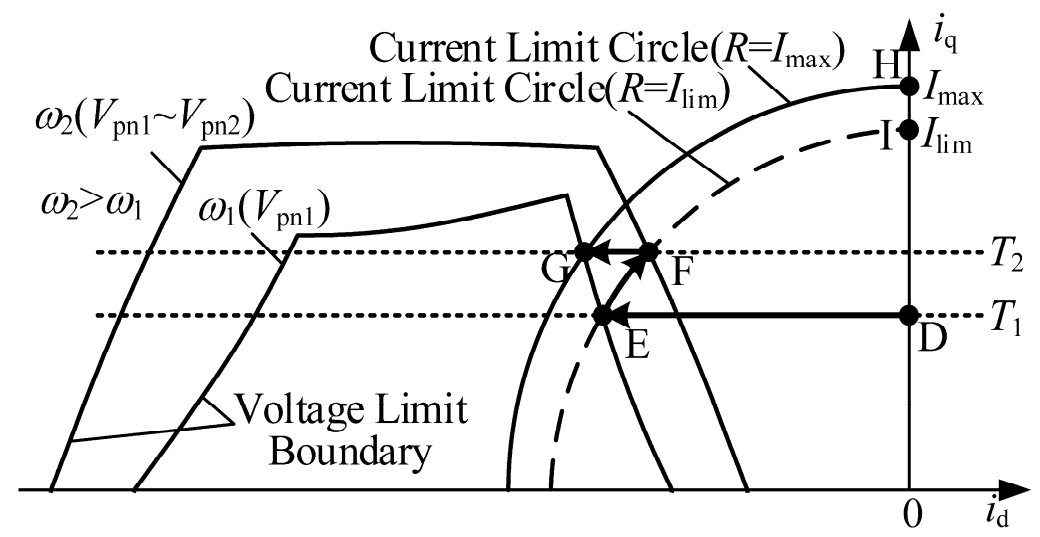

Figure 6. Trajectory of operation point with the proposed strategy in the flux-weakening region.

Assume the current operation point is located at Point E, i.e., speed of SPMSM is $\omega_{1}$ and load torque is $T_{1}$. In the area of speed below $\omega_{1}, \Delta v_{\mathrm{q}} \geq 0$ and $I_{\text {ref }} \leq I_{\text {lim }}$, and only PART_1 works. If speed and torque increase synchronously to $\omega_{2}$ and $T_{2}$, respectively, the operation point moves to Point $F$ along the arc of EF. During the process, $\Delta v_{\mathrm{q}} \geq 0$, $I_{\text {ref }}>I_{\text {lim }}$, the actual current of SPMSM reaches $I_{\text {lim }}$, and PART_2 works. As a result, when the endpoint of the stator current vector exceeds the current limit circle ( $R=I_{\text {lim }}, R$ is the radius of the limit circle), the rectifier stage modulation depth controller increases the output voltage of the IMC by increasing $\alpha$, which means the voltage boundary enlarged and the endpoint of the current vector is pulled back to the current limit circle $\left(R=I_{\text {lim }}\right)$.

PART_2 reaches saturation if $\alpha$ reaches the maximum value of $\pi / 6$ at Point $F$. Then, the operation point moves to Point G along FG with speed increasing and the load torque unchanged by keeping the rectifier stage only working in the modulation mode of CASE 2 .

It should be noticed that when operating at low speeds and heavy loads, such as the line segment HI in Figure 6, the stator current may exceed the limit although SPMSM is not in the flux-weakening region. Then, the modulation depth controller adjusts $\alpha$ to make the rectifier stage work in the over-modulation region, which is totally unnecessary 
and results in considerable harmonics in the voltage and current of SPMSM. Therefore, a step of judgement needs to be added in PART_2, as shown in Figure 1. Polarity of the flux-weakening current $i_{\mathrm{d}_{\mathrm{f}} \mathrm{fw}}$ is used to determine whether $\alpha$ should be set to zero or output of the regulator in PART_2.

Based on the above analysis, Figure 7 presents the flowchart of the proposed fluxweakening control strategy.

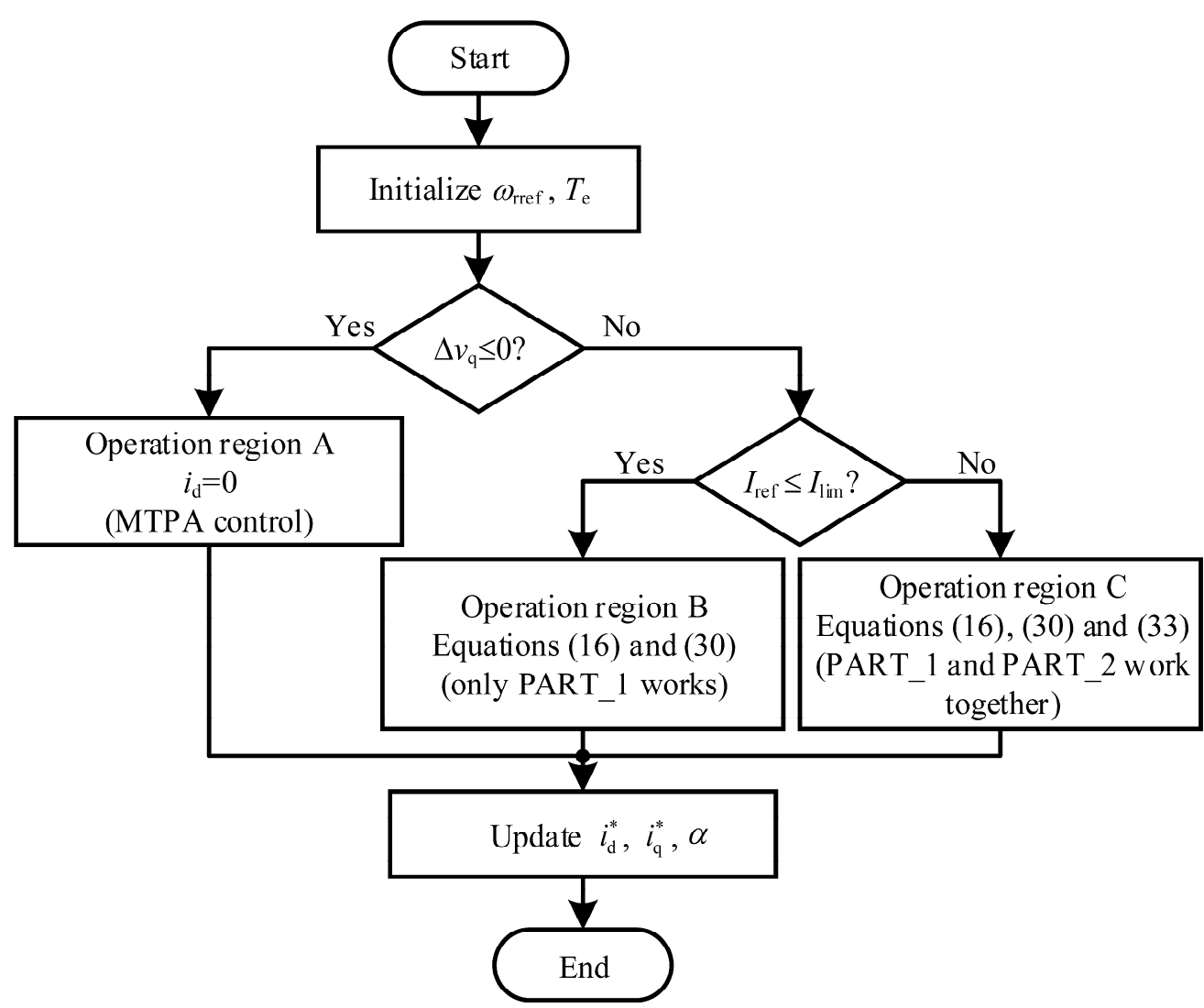

Figure 7. Flowchart of the proposed flux-weakening control strategy.

\section{Simulation Results}

\subsection{Simulation Parameter Setting}

To verify the effectiveness of the proposed flux-weakening control strategy, simulations were carried out with MATLAB/Simulink. In the simulation, a 4 kW SPMSM was used and its parameters are listed in Table 2. Three-phase input line-to-line voltage of the IMC was $380 \mathrm{~V} / 50 \mathrm{~Hz}$. It should be noted that in the linear modulation region, the output maximum line-to-line voltage root mean square (RMS) of the IMC-SPMSM was only 0.866 times of $380 \mathrm{~V}$. That is, for SPMSM shown in Table 2, it cannot operate under the rated conditions. Besides that, the maximum output current of the IMC was $15 \mathrm{~A}$. Inductance, resistance, and capacitance of the input filter were $0.8 \mathrm{mH}, 20 \Omega$, and $20 \mu \mathrm{F}$, respectively. The switching frequency of the IMC was $5 \mathrm{kHz}$. Parameters of the current regulator and speed regulator were adjusted according to the internal model principle, and bandwidth of the current loop was $3000 \mathrm{rad} / \mathrm{s}[21,22]$.

Setting $n \in[1300 \mathrm{r} / \mathrm{min}, 2500 \mathrm{r} / \mathrm{min}]$ with $\varphi_{v} \in[\pi / 2, \pi]$, the harmonic amplitude of the stator current in the flux-weakening region is analyzed to set $I_{\lim }$ (considering electric operation). According to (38), amplitudes of harmonics with frequency of $6 \omega_{\mathrm{i}}, 6 \omega_{\mathrm{o}}$, and $6\left(\omega_{\mathrm{o}}-\omega_{\mathrm{i}}\right)$ are calculated, and variation of them with $n$ and $\varphi_{v}$ are drawn in Figure 8 . Frequency of $6\left(\omega_{\mathrm{o}}+\omega_{\mathrm{i}}\right)$ is close to the current loop bandwidth and the corresponding harmonic is not considered. It can be seen from Figure 8 that the difference between $I_{\text {lim }}$ and $I_{\max }$ should be greater than $3 \mathrm{~A}$. As the harmonic is not always maximum during 
IMC-SPMSM operation, $I_{\text {lim }}$ is set to $12 \mathrm{~A}$, so as to tradeoff between the harmonics and performance of speed.

Table 2. Parameters of SPMSM.

\begin{tabular}{ccc}
\hline Parameters & Values & Quantities \\
\hline Rated power & 4 & $\mathrm{~kW}$ \\
Rated speed & 1500 & $\mathrm{r} / \mathrm{min}$ \\
Rated torque & 20 & $\mathrm{~N} \cdot \mathrm{m}$ \\
Rated voltage & 380 & $\mathrm{~V}$ \\
Rated current & 8.8 & $\mathrm{~A}$ \\
Stator resistance & 0.93 & $\Omega$ \\
Stator inductance & 19.8 & $\mathrm{mH}$ \\
Flux linkage of rotor & 1.0267 & $\mathrm{~Wb}$ \\
Number of pole pairs & 2 & - \\
Moment of inertia & 0.0065 & $\mathrm{~kg} \cdot \mathrm{m}^{2}$ \\
\hline
\end{tabular}

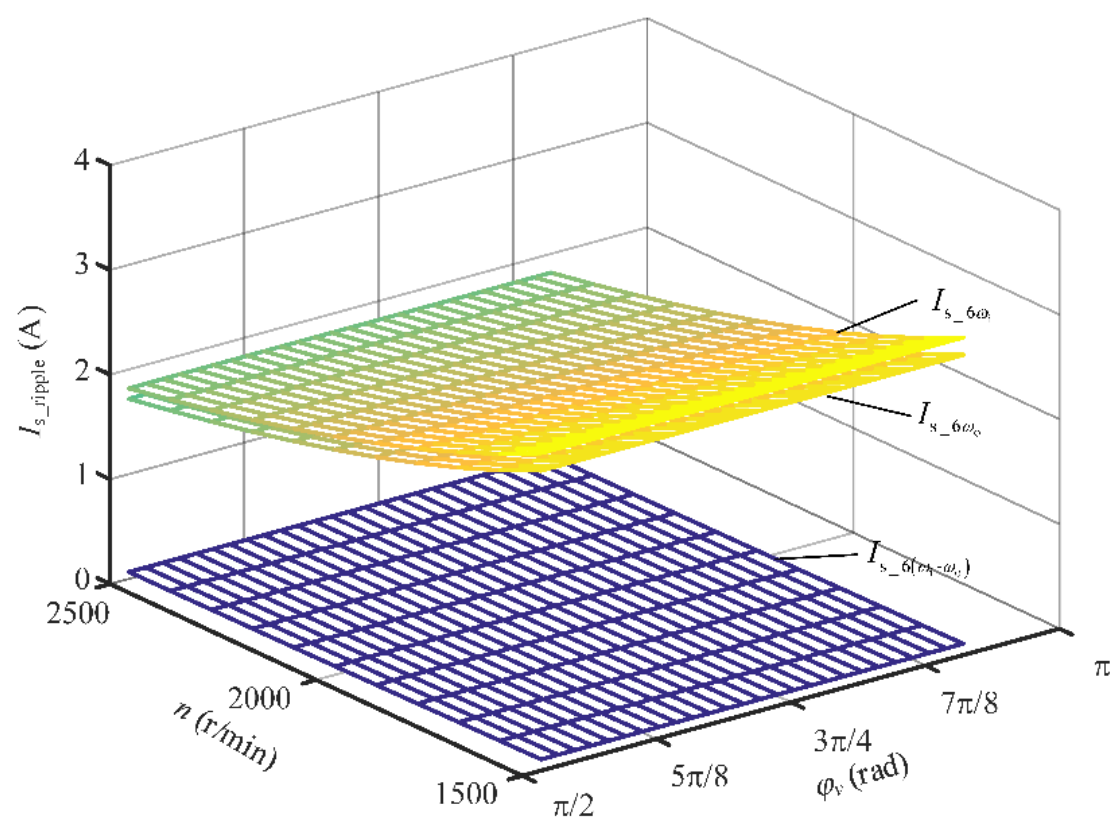

Figure 8. Stator current harmonics at different low-order frequencies.

\subsection{Function Analysis of Rectifier Stage Modulation Depth Controller}

Figure 9 shows the simulation result of the maximum torque curve at different speeds, where Curves A, B, and C represent the torque-speed characteristic curves under $i_{\mathrm{d}}=0$ control, only PART_1 control, and PART_1 + PART_2 control, respectively. It can be seen from Figure 9 that under the same load torque, the speed range of Curve $B$ and $C$ is about $30 \%$ and $35 \%$ larger than that of Curve A, respectively.

Simulation results of acceleration from 1500 to $1750 \mathrm{r} / \mathrm{min}$ with a load torque of $10 \mathrm{~N} \cdot \mathrm{m}$ are compared in Figure 10, where $n_{1}, T_{\mathrm{e} 1}, I_{\mathrm{s} 1}$ and $n_{2}, T_{\mathrm{e} 2}, I_{\mathrm{s} 2}$ are waveforms of speed, torque, and stator current, using PART_1 control and PART_1+PART_2 control, respectively.

As can be seen from Figure 10, the rising time of $n_{2}$ is shorter than that of $n_{1}$, and the steady torque ripple of $T_{\mathrm{e} 2}$ is larger than $T_{\mathrm{e} 1}$. As the stator current is greater than $I_{\mathrm{lim}}$, PART_2 plays its role to adjust $I_{\mathrm{s} 2}$ to be close to $I_{\mathrm{lim}}$. Consequently, although the rising time is improved due to the broadened voltage margin of the rectifier stage in the mode of over-modulation, the torque ripple is enlarged because of increased current harmonics. 


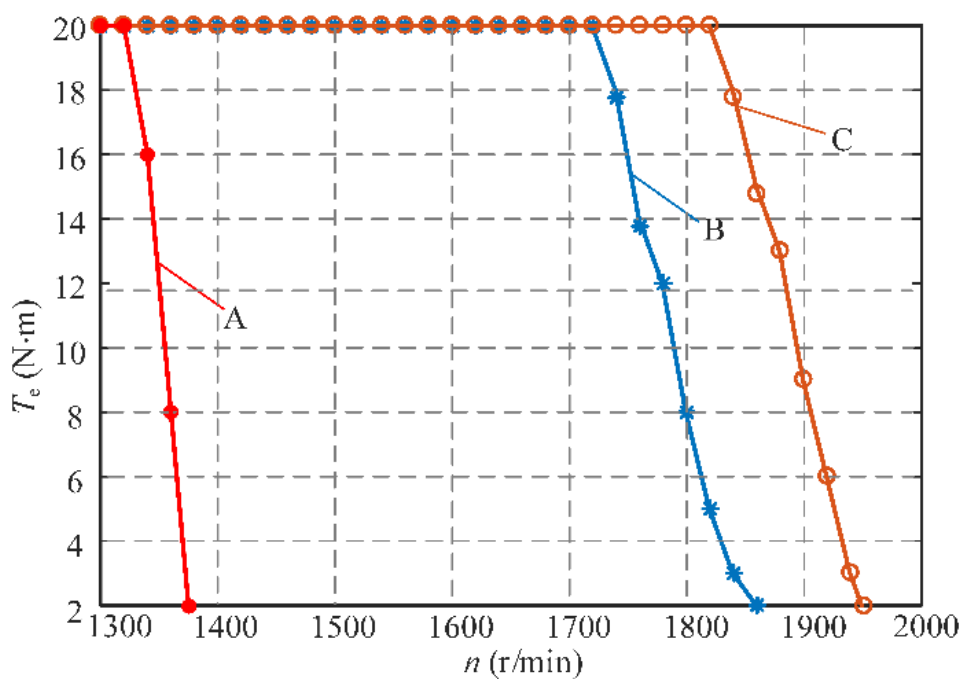

Figure 9. Simulation diagram of motor torque speed characteristic curve.
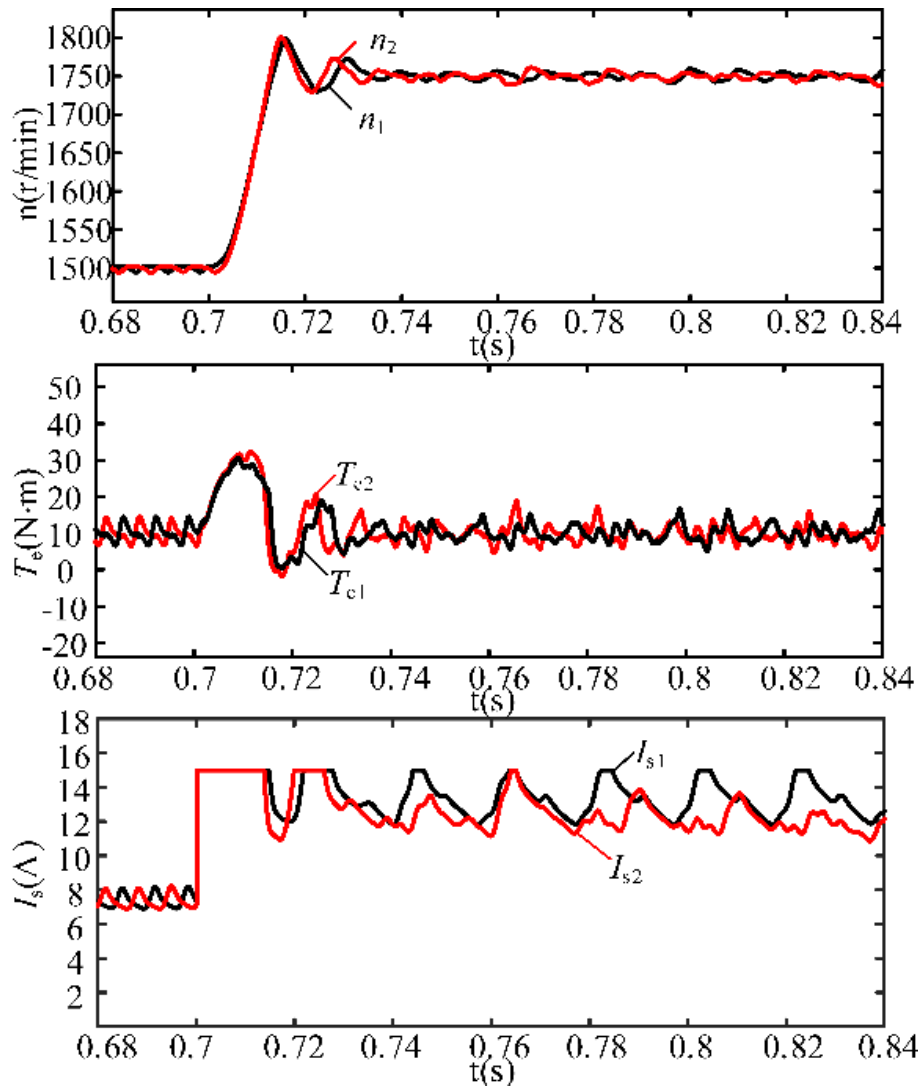

Figure 10. Simulation waveform comparison diagram of only PART_1 control and PART_1 + PART_2 control.

5.3. Control Performance Analysis of the Proposed Strategy in Different Operation Regions 5.3.1. Operation Region A

Figure 11 shows the simulation results of the no-load starting of SPMSM, accelerating from 1000 to $1200 \mathrm{r} / \mathrm{min}$ at $0.1 \mathrm{~s}$ and loading to $10 \mathrm{~N} \cdot \mathrm{m}$ at $0.2 \mathrm{~s}$. SPMSM is controlled by the $i_{\mathrm{d}}=0$ method and the IMC works in the linear modulation region. The operation point is located in Region A of Figure 2. 

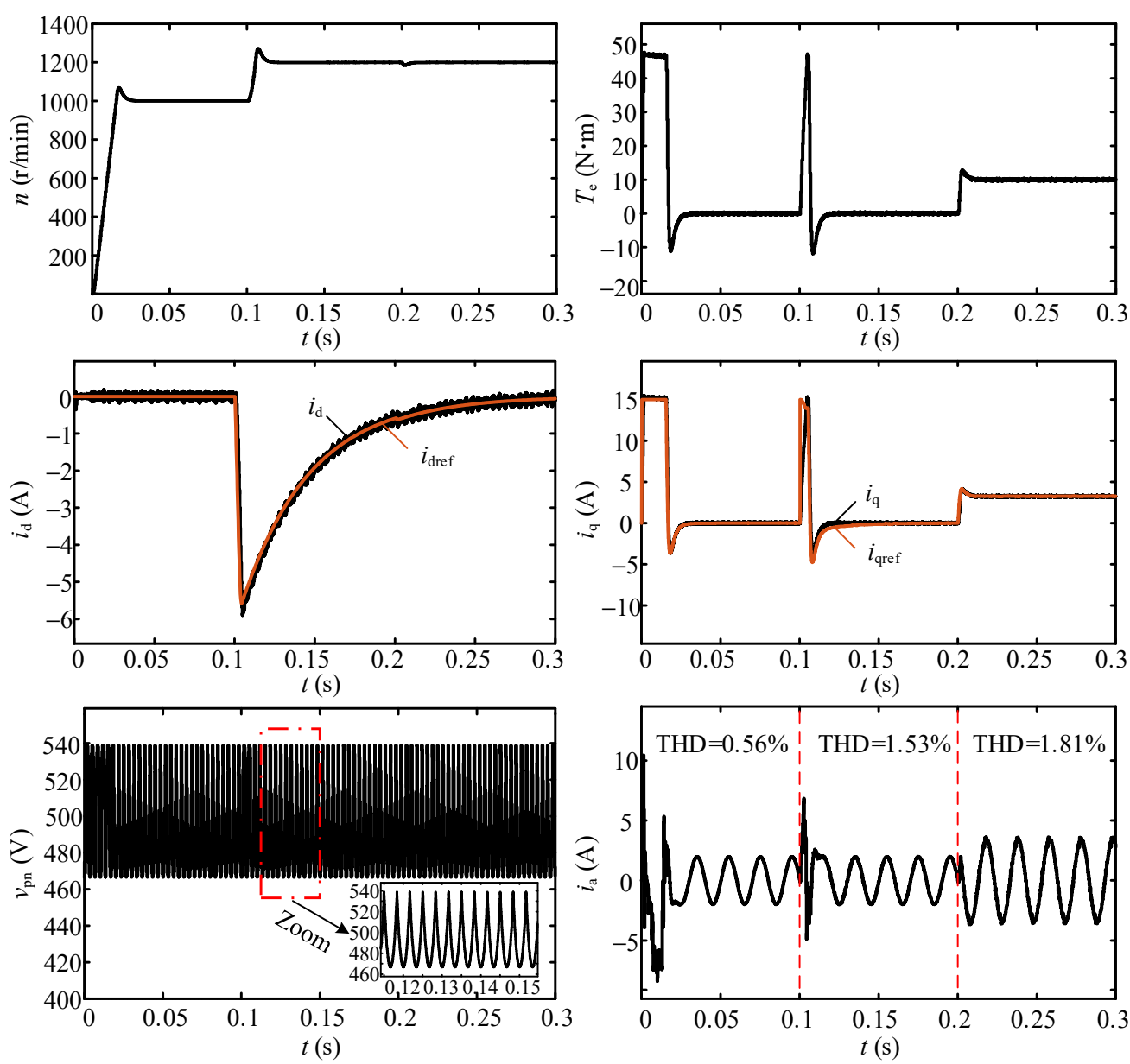

Figure 11. Simulation waveforms of operation Region A.

In the figure, actual speed traces the reference well. The IMC is in the linear modulation region, and the rectifier stage keeps CASE 1 modulation. Total harmonic distortion (THD) of one of the input currents of Phase a of the IMC, $i_{\mathrm{a}}$, is $7.89 \%$. Torque ripple of SPMSM is nearly the peak-to-peak value of $0.8 \mathrm{~N} \cdot \mathrm{m}$ with peak and valley values of 10.4 and $9.6 \mathrm{~N} \cdot \mathrm{m}$.

\subsubsection{Operation Region B}

Figure 12 shows the simulation results of operation Region B of Figure 2. The speed of SPMSM increases from 1200 to $1500 \mathrm{r} / \mathrm{min}$ with a load torque of $10 \mathrm{~N} \cdot \mathrm{m}$. Both overmodulation and flux-weakening control are put into operation for the inverter stage.

In Figure 12, performance of speed tracing is close to that in Figure 11. Harmonics of stator currents of SPMSM increase, as the inverter stage works in the mode of minimum phase error over-modulation. Torque ripple increases to nearly $7 \mathrm{~N} \cdot \mathrm{m}$, with peak and valley values of 14 and $7 \mathrm{~N} \cdot \mathrm{m}$. THD of input currents of the IMC is also increased to $18.16 \%$, with most harmonic contents focusing at frequencies of 250 and $350 \mathrm{~Hz}$. During acceleration, the reference current is greater than $I_{\text {lim }}$, which triggers PART_2 to increase $\alpha$, and then the output of the rectifier stage is improved. At the end of acceleration, the rectifier stage exits from the over-modulation region, and the IMC is in the state of over-modulation I. In the figure, the waveform of $\bar{v}_{\mathrm{pn}}$ is zoomed in to show its variation with respect to $\alpha$ during acceleration.

\subsubsection{Operation Region C}

Figure 13 shows simulation results of operation Region C of Figure 2. The speed of SPMSM increases from 1500 to $1750 \mathrm{r} / \mathrm{min}$ with a load torque of $10 \mathrm{~N} \cdot \mathrm{m}$. 

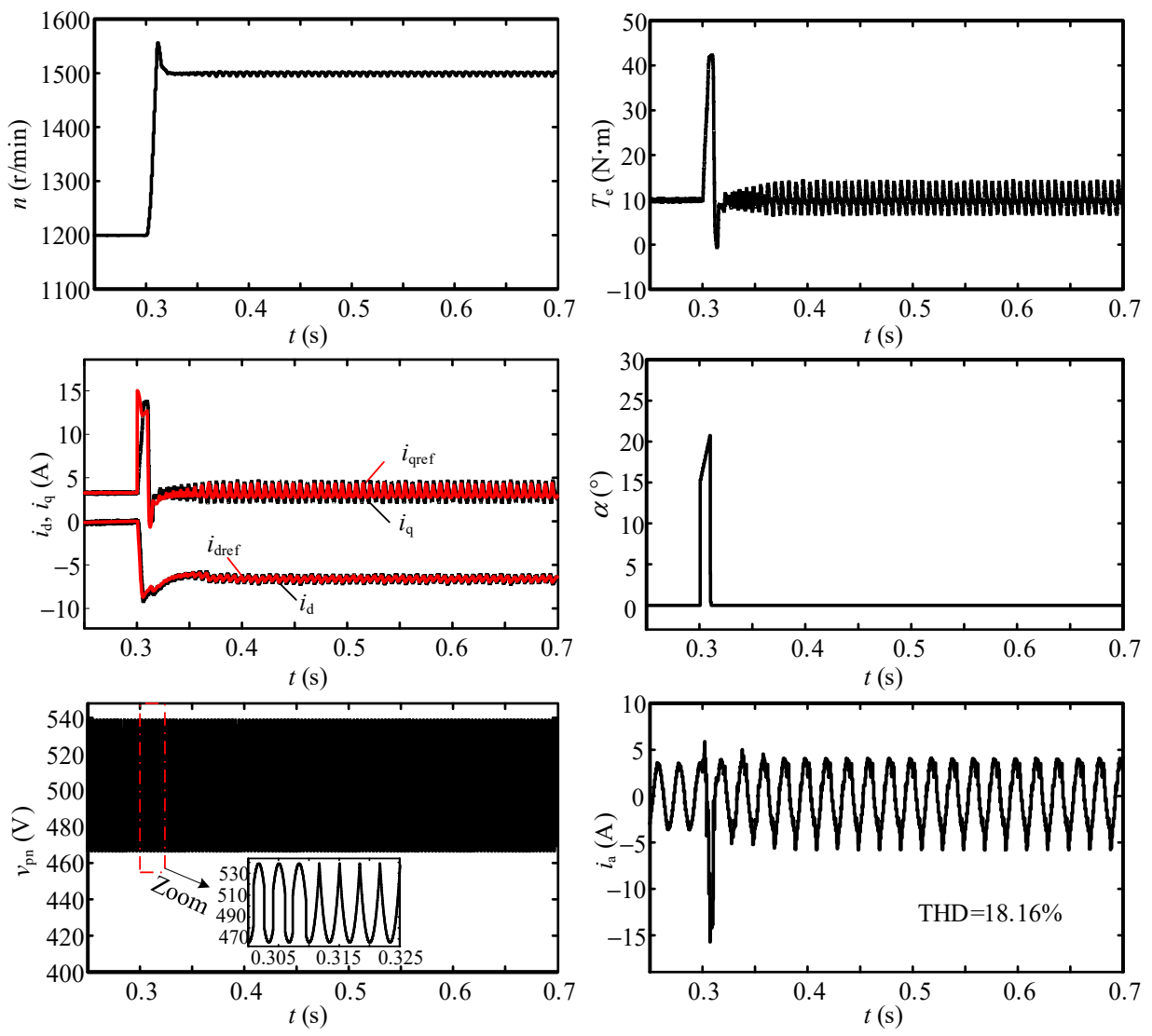

Figure 12. Simulation waveforms of operation Region B.
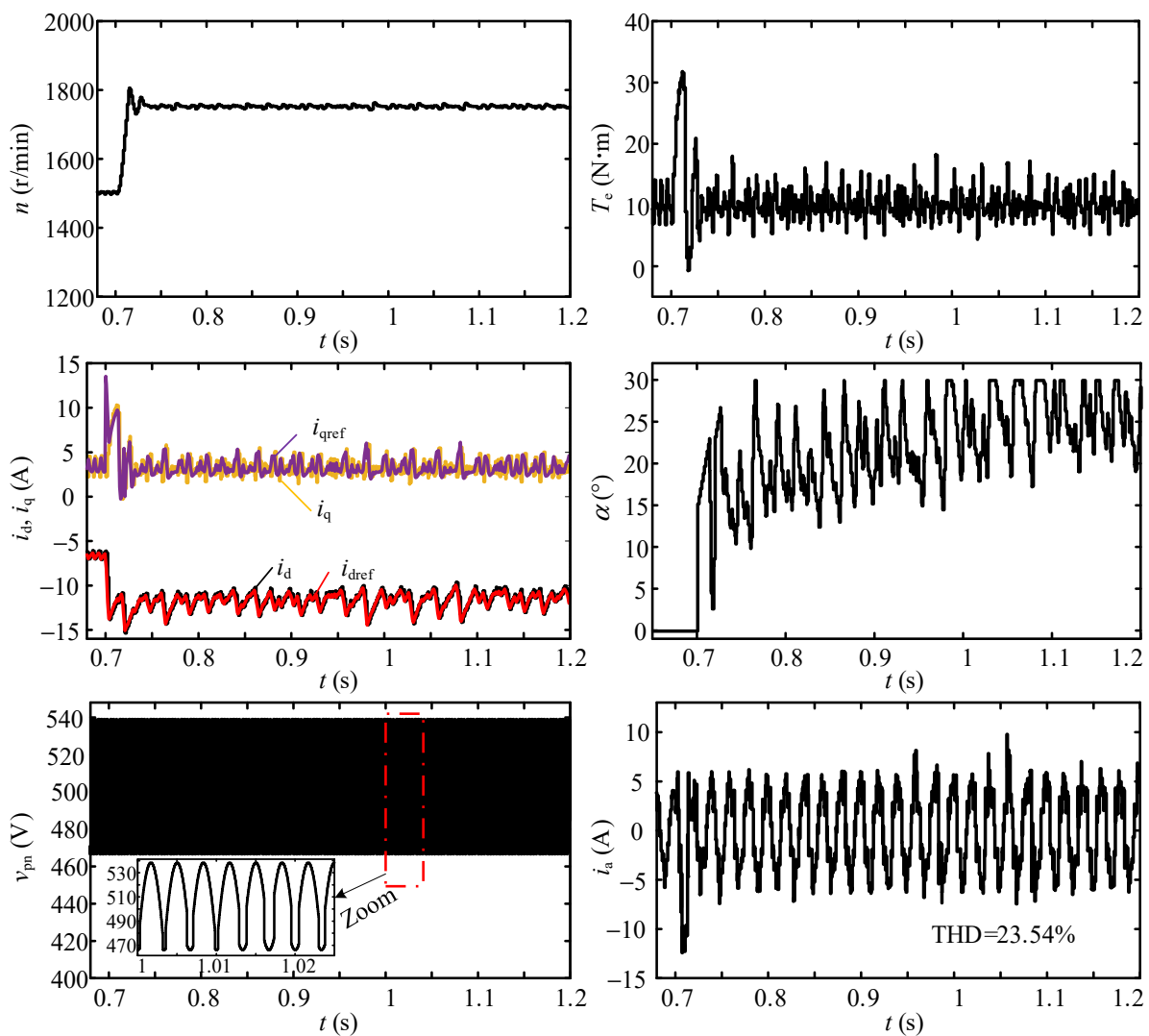

Figure 13. Simulation waveforms of operation Region C. 
In the figure, the reference current is greater than $I_{\lim }$ and PART_2 works. Waveforms of $\bar{v}_{\mathrm{pn}}$ in the steady state, which is constituted by $\bar{v}_{\mathrm{pn} 1}$ and $\bar{v}_{\mathrm{pn} 2}$ proportionally according to $\alpha$, are shown in the figure. The IMC is in the state of over-modulation II. Harmonic distortion of input current of the IMC appears more severe with THD increasing to $23.54 \%$, as the IMC rectifier stage enters the over-modulation region. Energy of the harmonics mainly concentrate at 250 and $350 \mathrm{~Hz}$. In operation Region C, torque ripple is larger compared with that in other regions, and its peak-to-peak value reaches nearly $10 \mathrm{~N} \cdot \mathrm{m}$.

\section{Experimental Results}

\subsection{System Parameter Setting}

Experiments were carried out based on the prototype shown in Figure 14 to verify the proposed flux-weakening control strategy. Inductance, resistance, and capacitance of the input filter were $0.8 \mathrm{mH}, 20 \Omega$, and $20 \mu \mathrm{F}$, respectively. The switching frequency of the IMC was $5 \mathrm{kHz}$. Parameters of SPMSM are shown in Table 2. To be explained is that the withstanding voltage of the filter capacitor and clamp circuit capacitance of the prototype was not high enough, and the three-phase input line-to-line voltage of the IMC was set to $150 \mathrm{~V} / 50 \mathrm{~Hz}$ during the tests. The maximum output current of the IMC was $8.8 \mathrm{~A}$ and $I_{\text {lim }}$ was set to $6 \mathrm{~A}$.

\subsection{Experimental Analysis of Speed Range of IMC-SPMSM under the Proposed Strategy}

Figure 15 shows the maximum torque curve of the prototype at different speeds, where Curves a, $\mathrm{b}$, and $\mathrm{c}$ represent the torque-speed characteristic curves under $i_{\mathrm{d}}=0$ control, only PART_1 control, and PART_1 + PART_2 control, respectively. It can be seen from Figure 15 that under the same load torque, the speed range of Curve $b$ and $c$ is about $30 \%$ and $35 \%$ larger than that of Curve a, respectively.

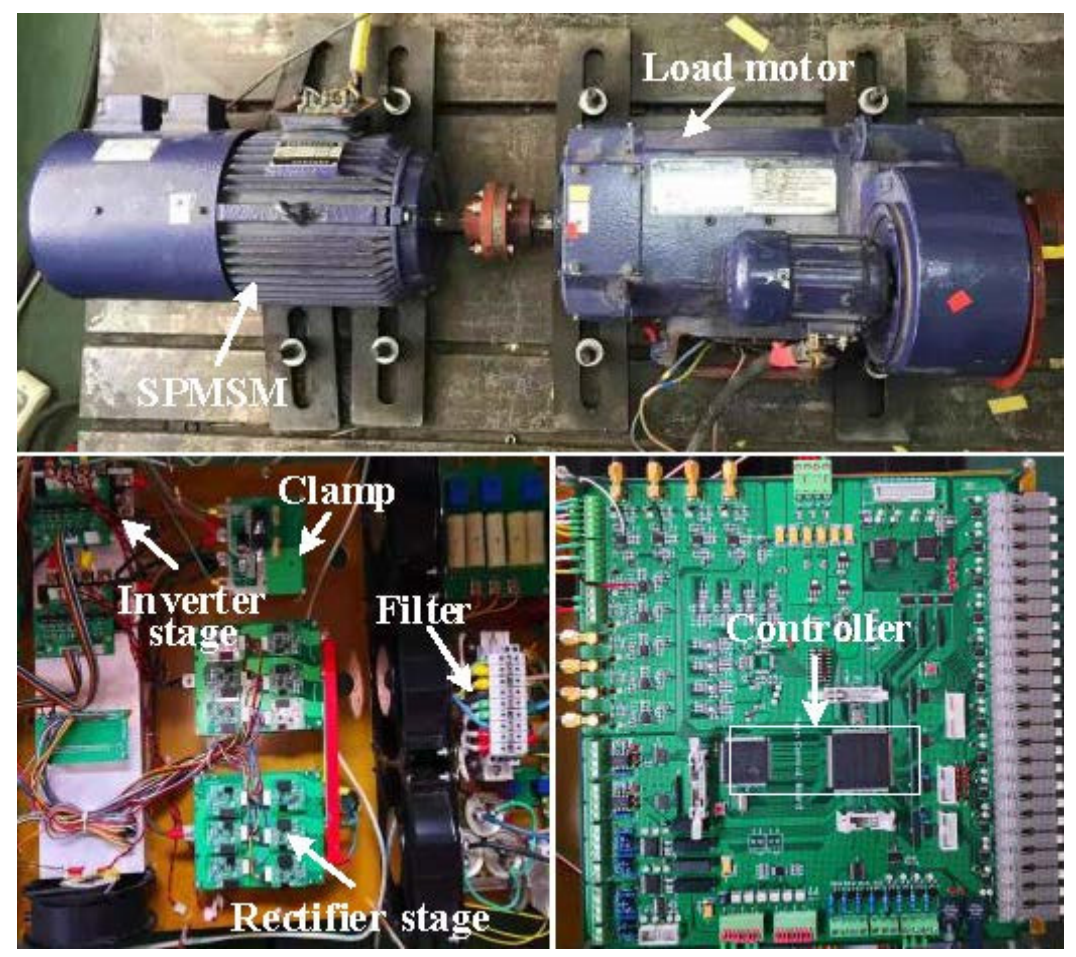

Figure 14. Experimental prototype of IMC-SPMSM. 


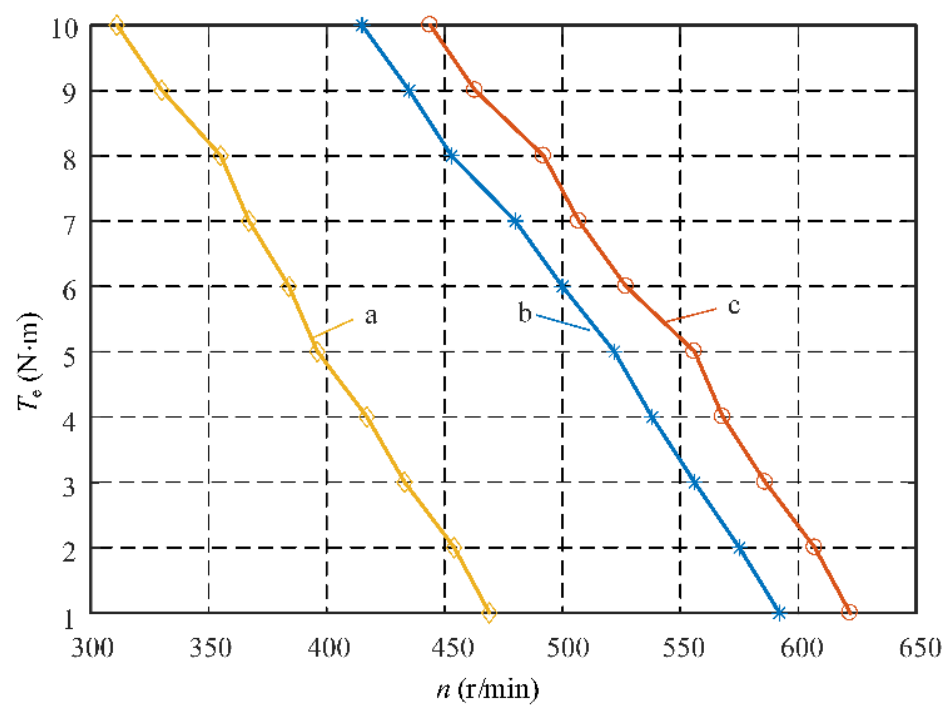

Figure 15. Experimental diagram of motor torque speed characteristic curve.

\subsection{Function Analysis of Over-Modulation Depth Controller}

Experimental results of acceleration from 200 to $550 \mathrm{r} / \mathrm{min}$ with a load torque of $5 \mathrm{~N} \cdot \mathrm{m}$ are compared in Figure 16, where $n_{1}, T_{\mathrm{e} 1}, I_{\mathrm{s} 1}$ and $n_{2}, T_{\mathrm{e} 2}, I_{\mathrm{s} 2}$ are waveforms of speed, torque, and stator current, using PART_1 control and PART_1 + PART_2 control, respectively.
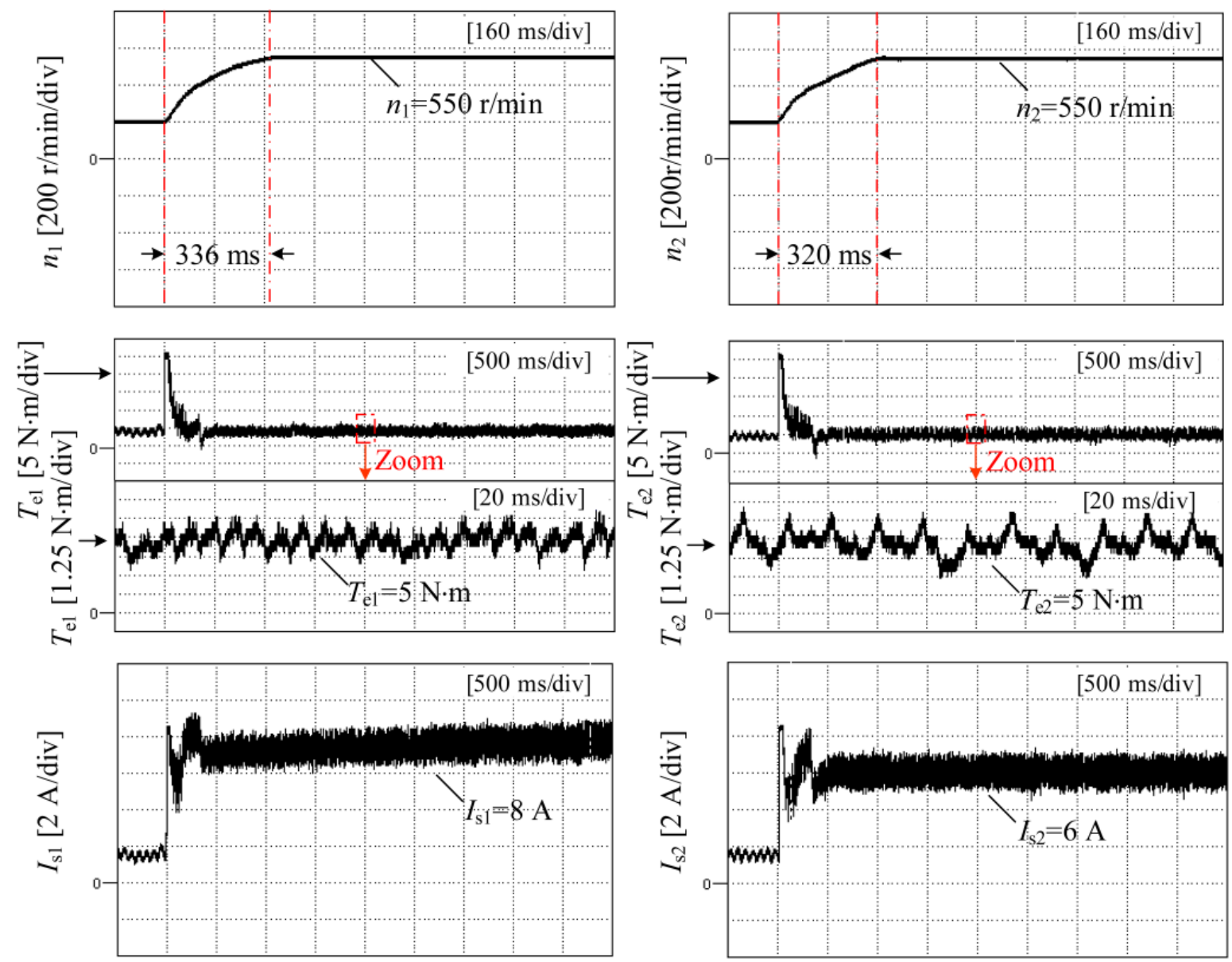

Figure 16. Waveform comparison diagram of only PART_1 control and PART_1+PART_2 control. 
As can be seen from Figure 16, the rising time of $n_{2}$ is about $4.8 \%$ shorter than that of $\mathrm{n}_{1}$, and the steady torque ripple of $\mathrm{T}_{\mathrm{e} 2}$ is reduced by about $20 \%$ compared with that of $\mathrm{T}_{\mathrm{e} 1}$, from 5 to $4 \mathrm{~N} \cdot \mathrm{m}$, which implies performance improved both in transient and steady states. As the stator current is greater than $\mathrm{I}_{\text {lim }}$, PART_2 plays its role to adjust $\mathrm{I}_{\mathrm{s} 2}$ to be close to $\mathrm{I}_{\text {lim. }}$. Consequently, although the setting time is shortened due to the broadened voltage margin of the rectifier stage in the mode of over-modulation, the torque ripple is enlarged because of increased current harmonics.

\subsection{Control Performance Analysis of the Proposed Strategy in Different Operation Regions 6.4.1. Operation Region A}

Figure 17 shows the experimental results of no-load starting with the steady speed of $300 \mathrm{r} / \mathrm{min}$ and step load of $5 \mathrm{~N} \cdot \mathrm{m}$. SPMSM is controlled by the $i_{\mathrm{d}}=0$ method and the IMC works in the linear modulation region. Correspondingly, the operation point is located in Region A of Figure 2.
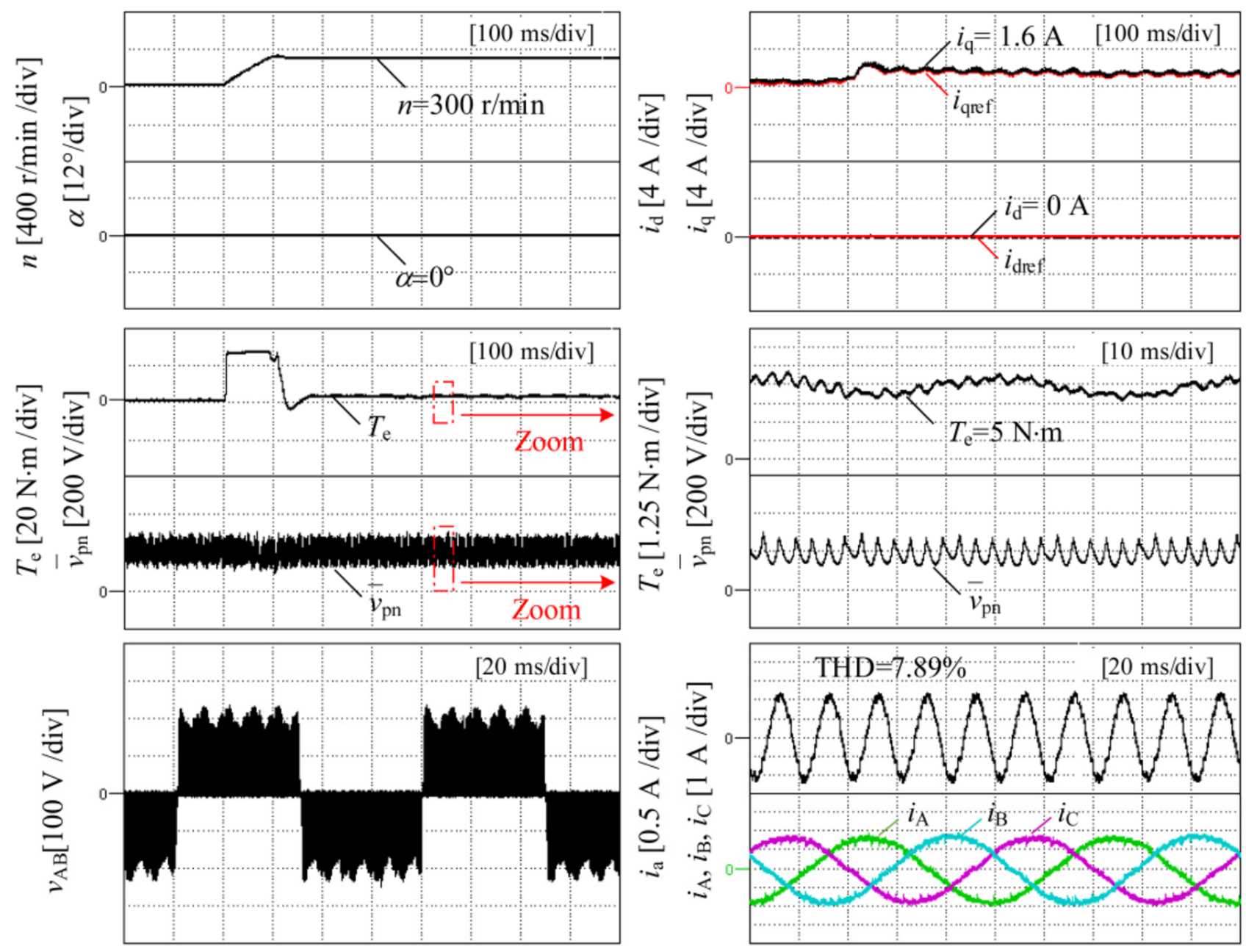

Figure 17. Experimental waveforms of operation Region A.

In the figure, actual speed traces the reference well. The IMC is in the linear modulation region, and modulation depth angle, $\alpha$, remains to be 0 . The rectifier stage keeps CASE 1 modulation, and there is no distortion caused by over-modulation in the shape of output voltage of the IMC. Output currents of the IMC, $i_{\mathrm{A}}, i_{\mathrm{B}}$, and $i_{\mathrm{C}}$, are very close to the sinusoid and are of less distortion. THD of one of the input currents of Phase a of the IMC, $i_{\mathrm{a}}$, is $7.89 \%$, which is calculated from data of scope. The torque ripple of SPMSM is nearly the peak-to-peak value of $2 \mathrm{~N} \cdot \mathrm{m}$. 


\subsubsection{Operation Region B}

Figure 18 shows the experimental results of operation Region B of Figure 2. The speed of SPMSM increases from 300 to $400 \mathrm{r} / \mathrm{min}$ with a load torque of $5 \mathrm{~N} \cdot \mathrm{m}$. Both over-modulation and flux-weakening control are put into operation for the inverter stage.
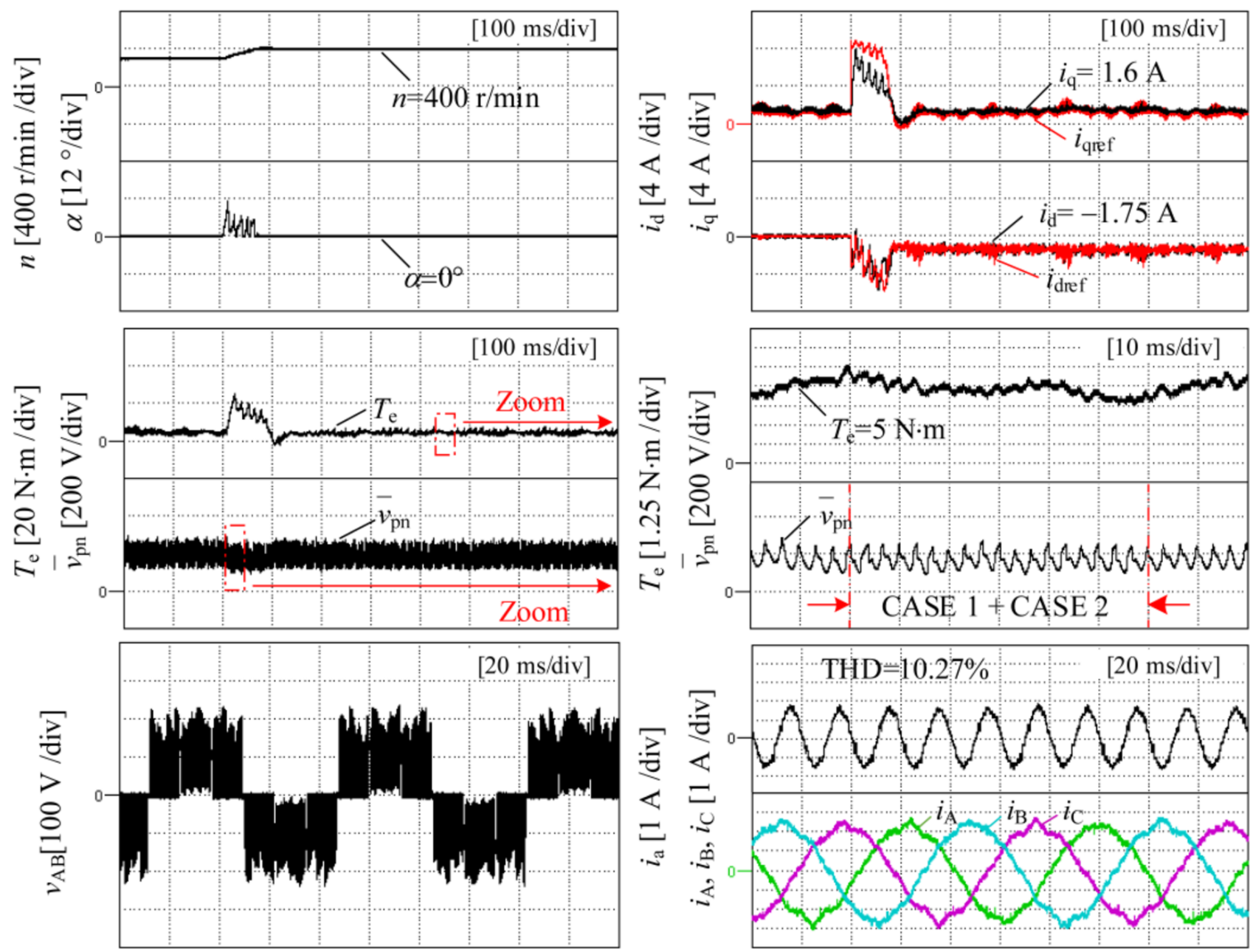

Figure 18. Experimental waveforms of operation Region B.

In Figure 18, performance of speed tracing is close to that in Figure 17. The contour of $v_{\mathrm{AB}}$ appears as an irregular shape and the harmonics of stator currents of SPMSM increase, as the inverter stage works in the mode of minimum phase error over-modulation. Torque ripple increases to nearly $2.5 \mathrm{~N} \cdot \mathrm{m}$, with peak and valley values of 6.25 and $3.75 \mathrm{~N} \cdot \mathrm{m}$. THD of input currents of the IMC is also increased to $10.27 \%$, with most harmonic contents focusing at frequencies of 250 and $350 \mathrm{~Hz}$. During acceleration, the reference current is greater than $I_{\mathrm{lim}}$, which triggers PART_2 to increase $\alpha$, and then the output of the rectifier stage is improved. At the end of acceleration, the rectifier stage exits from the over-modulation region, and the IMC is in the state of over-modulation I. In the figure, the waveform of $\bar{v}_{\mathrm{pn}}$ is zoomed in to show its variation with respect to $\alpha$ during acceleration.

\subsubsection{Operation Region C}

Figure 19 shows experimental results of operation Region $C$ of Figure 2. The speed of SPMSM increases from 400 to $550 \mathrm{r} / \mathrm{min}$ with a load torque of $5 \mathrm{~N} \cdot \mathrm{m}$. 

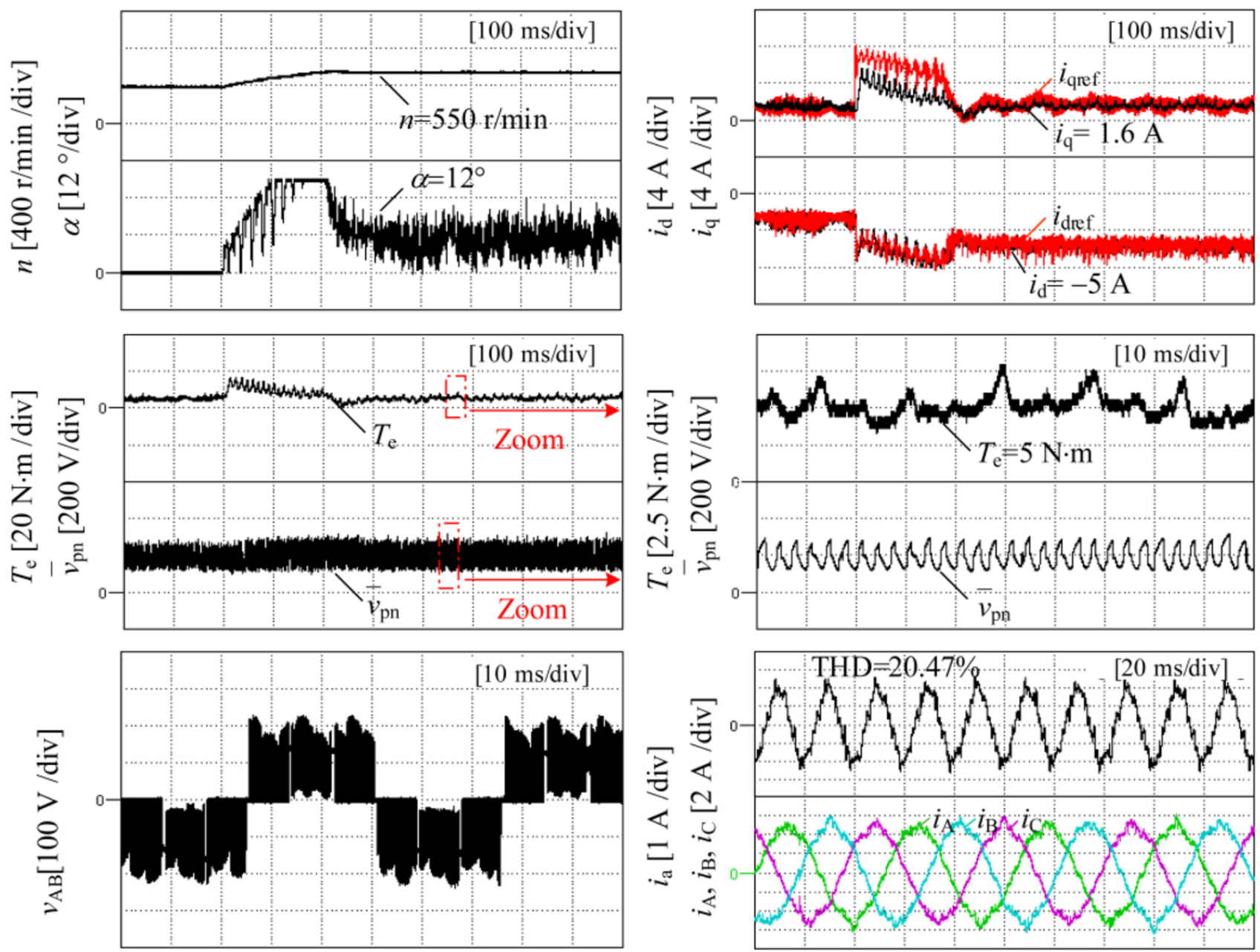

Figure 19. Experimental waveforms of operation Region C.

In the figure, harmonic distortion of input current of the IMC appears more severe with THD increasing to $20.47 \%$, as the IMC rectifier stage enters the over-modulation region. Energy of the harmonics mainly concentrate at 118 and $250 \mathrm{~Hz}$. Similarly, distortion of stator currents of SPMSM is also increased due to deeper over-modulation of the inverter stage, which can also be deduced from the waveform of $v_{\mathrm{AB}}$. In operation Region $\mathrm{C}$, the torque ripple is larger compared with that in other regions, and its peak-to-peak value reaches nearly $5 \mathrm{~N} \cdot \mathrm{m}$. Waveforms of $\bar{v}_{\mathrm{pn}}$ in the steady state, which is constituted by $\bar{v}_{\mathrm{pn} 1}$ and $\bar{v}_{\mathrm{pn} 2}$ proportionally according to $\alpha$, are shown in the figure. The IMC is in the state of over-modulation II.

According to the above simulation and experimental results, it can be seen that the wide speed range operation strategy proposed in this paper for the IMC-SPMSM has the following characteristics: (1) actual speed can trace the given value well, and there is no error in the steady state; (2) keep motor speed constant and add torque suddenly, and speed can be quickly recovered after dynamic descent; keep torque unchanged, suddenly increase speed, and torque can quickly fall after dynamic increase, so the anti-interference performance is satisfactory.

\section{Conclusions}

Aiming to improve the speed range for the IMC-SPMSM, a wide-speed range operation control strategy including over-modulation and flux-weakening control was proposed in this paper. The proposed strategy improves VTR of the fundamental output voltage of the IMC from 0.866 to 1 by coordinating over-modulation of both the rectifier stage and in- 
verter stage. At the inverter stage, a flux-weakening controller was designed to control the d-axis current of SPMSM. Determination of a proportional coefficient of the flux-weakening controller, $\beta$, which affects both transient and steady-state performance of SPMSM, was discussed to tradeoff between load capacity and dynamic performance according to work conditions. At the rectifier stage, a modulation depth controller was designed to adjust the output voltage of the rectifier to further expand the speed regulation range. To avoid unexpected saturation, the current limit for the controller, $I_{\text {lim }}$, should be cautiously selected considering the harmonic current of SPMSM caused by over-modulation, as $I_{\text {lim }}$ contributes to the threshold used to judge whether the modulation depth controller starts to work or not. In practice, the value of $I_{\text {lim }}$ needs to be fine-tuned based on theoretical calculations as actual harmonics are hard to be precisely evaluated. Finally, experimental results verify feasibility of the proposed strategy. The maximum speed was nearly $35 \%$ higher compared with that of the MTPA strategy, and the setting time was also shortened, benefiting from the extra voltage margin by over-modulation of the rectifier stage. In the following research, we will further improve the prototype and test the proposed strategy under full voltage conditions. On the other hand, under flux-weakening conditions, strategy optimization considering load capacity and efficiency will also be the focus of the next step of research.

Author Contributions: Conceptualization, Validation, and Writing-Original draft, N.Z.; Formal analysis, P.S.; Funding acquisition, T.S.; Software, N.Z.; Project administration, Y.Y.; Investigation, Y.Y.; Writing-Review and editing, Y.Y., P.S., and T.S. All authors have read and agreed to the published version of the manuscript.

Funding: This research was funded by National Natural Science Foundation of China grant number [51777135] and Major Program of National Natural Science Foundation of China grant number [51991384].

Institutional Review Board Statement: "Not applicable" for studies not involving humans.

Informed Consent Statement: “Not applicable” for studies not involving humans.

Data Availability Statement: Data available on request due to restrictions, e.g., privacy or ethics. The data presented in this study are available on request from the corresponding author. The data are not publicly available due to the need for further research.

Conflicts of Interest: The authors declare no conflict of interest.

\section{References}

1. Wang, C.; Zhu, Z.Q.; Zhan, H. Adaptive Voltage Feedback Controllers on Nonsalient Permanent Magnet Synchronous Machine. IEEE Trans. Ind. Appl. 2020, 56, 1529-1542. [CrossRef]

2. Dong, Z.; Wang, B.; Yu, Y. Operating Point Selected Flux-Weakening Control of Induction Motor for Torque-Improved High-Speed Operation Under Multiple Working Conditions. IEEE Trans. Power Electron. 2019, 34, 12011-12023. [CrossRef]

3. Tursini, M.; Chiricozzi, E.; Petrella, R. Feedforward Flux-Weakening Control of Surface-Mounted Permanent-Magnet Synchronous Motors Accounting for Resistive Voltage Drop. IEEE Trans. Ind. Electron. 2010, 57, 1632-1637. [CrossRef]

4. Wang, S.; Kang, J.; Degano, M.; Galassini, A.; Gerada, C. An Accurate Wide-speed Range Control Method of IPMSM Considering Resistive Voltage Drop and Magnetic Saturation. IEEE Trans. Ind. Electron. 2020, 67, 2630-2641. [CrossRef]

5. Bedetti, N.; Calligaro, S.; Petrella, R. Analytical Design and Autotuning of Adaptive Flux-Weakening Voltage Regulation Loop in IPMSM Drives with Accurate Torque Regulation. IEEE Trans. Ind. Appl. 2020, 56, 301-313. [CrossRef]

6. Liu, H.; Zhu, Z.Q.; Mohamed, E. Flux-Weakening Control of Nonsalient Pole PMSM Having Large Winding Inductance, Accounting for Resistive Voltage Drop and Inverter Nonlinearities. IEEE Trans. Power Electron. 2012, 27, 942-952. [CrossRef]

7. Lin, P.Y. Voltage Control Technique for the Extension of DC-Link Voltage Utilization of Finite-Speed SPMSM Drives. IEEE Trans. Ind. Electron. 2012, 59, 3392-3402. [CrossRef]

8. Nalepa, R.; Orlowska, K.T. Optimum Trajectory Control of the Current Vector of a Nonsalient-Pole PMSM in the Field-Weakening Region. IEEE Trans. Ind. Electron. 2012, 59, 2867-2876. [CrossRef]

9. Kim, D.Y.; Lee, J.H. Optimum Low Cost Simple Look-Up Table-Based PMSM Drive Considering DC-Link Voltage Variation. Energies 2020, 13, 3904. [CrossRef]

10. Li, Y.; Qiu, L.; Zhi, Y.J. An Overmodulation Strategy for Matrix Converter Under Unbalanced Input Voltages. IEEE Access 2021, 9 , 2345-2356. [CrossRef]

11. Padhee, V.; Sahoo, A.K.; Mohan, N. Modulation Techniques for Enhanced Reduction in Common-Mode Voltage and Output Voltage Distortion in Indirect Matrix Converters. IEEE Trans. Power Electron. 2017, 32, 8655-8670. [CrossRef] 
12. Empringham, L.; Kolar, J.W.; Rodriguez, J. Technological issues and industrial application of matrix converter. IEEE Trans. Power Electron. 2016, 31, 1811-1815. [CrossRef]

13. Xia, Y.H.; Zhang, X.F.; Qiao, M.Z. Research on a new indirect space-vector overmodulation strategy in matrix converter. IEEE Trans. Ind. Electron. 2016, 63, 1130-1141. [CrossRef]

14. Li, S.; Xia, C.; Yan, Y. Space-Vector Overmodulation Strategy for Ultrasparse Matrix Converter Based on the Maximum Output Voltage Vector. IEEE Trans. Power Electron. 2017, 32, 5388-5397. [CrossRef]

15. Zhang, G.; Yang, J.; Sun, Y.; Su, M.; Zhu, Q.; Blaabjerg, F. A Predictive-Control-Based Over-Modulation Method for Conventional Matrix Converters. IEEE Trans. Power Electron. 2018, 33, 3631-3643. [CrossRef]

16. Tsoupos, A.; Khadkikar, V. A Novel SVM Technique with Enhanced Output Voltage Quality for Indirect Matrix Converters. IEEE Trans. Ind. Electron. 2019, 66, 832-841. [CrossRef]

17. Morimoto, S.; Takeda, Y.; Hirasa, T. Expansion of operating limits for permanent magnet motor by current vector control considering inverter capacity. IEEE Trans. Ind. Appl. 1990, 26, 866-871. [CrossRef]

18. Lin, F.J.; Liao, Y.H.; Lin, J.R. Interior Permanent Magnet Synchronous Motor Drive System with Machine Learning-Based Maximum Torque per Ampere and Flux-Weakening Control. Energies 2021, 14, 346. [CrossRef]

19. Li, S.; Chen, W.; Yan, Y. A Multi-mode Space Vector Overmodulation Strategy for UltraSparse Matrix Converter with Improved Fundamental Voltage Transfer Ratio. IEEE Trans. Power Electron. 2018, 33, 6782-6793. [CrossRef]

20. Ding, D.; Wang, G.; Zhao, N. Enhanced Flux-Weakening Control Method for Reduced DC-link Capacitance IPMSM Drives. IEEE Trans. Power Electron. 2019, 34, 7788-7799. [CrossRef]

21. Xia, C.; Yan, Y.; Song, P. Voltage Disturbance Rejection for Matrix Converter-Based PMSM Drive System Using Internal Model Control. IEEE Trans. Ind. Electron. 2012, 59, 361-372.

22. Harnefors, L.; Nee, H.P. Model-based current control of AC machines using the internal model control method. IEEE Trans. Ind. Appl. 1998, 34, 133-141. [CrossRef] 